\title{
La internacionalización de la educación superior: Concepto y evolución del modelo en la Universidad de Costa Rica
}

\section{The internationalization of higher education: Concept and Model Evolution at the University of Costa Rica}

\author{
Yorleni Aguilar-Castillo \\ Universidad de Costa Rica \\ Oficina de Asuntos Internacionales y Cooperación Externa \\ San José, Costa Rica \\ yorleni.aguilar@ucr.ac.cr \\ ORCID: orcid.org/0000-0001-5690-2562
}

\author{
Alba Stella Riveros-Angarita ${ }^{2}$ \\ Asesora y Consultora Externa \\ San José, Costa Rica \\ sriver07@gmail.com \\ ORCID: orcid.org/0000-0001-7799-0717
}

Recibido: 16 enero 2015 Aceptado: 16 junio 2016 Corregido: 13 agosto 2016

\begin{abstract}
Resumen: Este artículo examina la evolución del concepto de internacionalización y diversos modelos de internacionalización de la educación superior desarrollados en el mundo. De forma específica, propone una definición del proceso de internacionalización de la UCR y describe el modelo que ha seguido desde su creación a la actualidad. Evidencia cómo este proceso ha contribuido al cumplimiento de la misión de la UCR, favoreciendo la mejora de sus programas académicos, formación del personal docente, administrativo y estudiantes, mediante estrategias de cooperación académica y de intercambio.
\end{abstract}

Palabras claves: Concepto de internacionalización, modelos de internacionalización, universidades, educación superior.

\begin{abstract}
This article examines the evolution of the concept of internationalization and diverse models of internationalization of higher education that have been developed in the world. It specifically proposes a definition for the process of internationalization at UCR and studies the model it has followed from its creation up to present. It makes evident how this process has contributed to the fulfillment of UCR's mission by favoring the improvement of its academic programs, training of its faculty, administrative staff, and students, by means of academic cooperation and exchange strategies.
\end{abstract}

Keywords: Concept of internationalization, models of internationalization, universities, higher education

1 Magister Profesional en Administración Universitaria, Bachiller en inglés y egresada de la Maestría en Literatura Inglesa, Universidad de Costa Rica. Funcionaria administrativa. Jefa, Sección de Cooperación Internacional de la Oficina de Asuntos Internacionales y Cooperación Externa, Universidad de Costa Rica, San José, Costa Rica.

2 Doctora en Ciencias Agrícolas (título equiparado a Doctorado Académico en la UCR) y Magister Profesional en Administración Universitaria de la Universidad de Costa Rica. Asesora, consultora, evaluadora externa o par académico en procesos de acreditación de la educación superior para América Latina. Autora de artículos en revistas y dos libros publicados: Prácticas de genética e Inducción de resistencia en plantas. Asesora, consultora y evaluadora externa en Acreditación y Administración Universitaria para América Latina. San José, Costa Rica. 


\section{Introducción}

La Universidad de Costa Rica (UCR) es la primera institución costarricense autónoma de cultura superior con carácter público, creada en el año 1940, consagrada a la enseñanza, la investigación, la acción social, la creación artística y la difusión del conocimiento. Conforme con la síntesis de UCR en cifras (UCR, 2015), esta Institución recibe más de 7.000 estudiantes nuevos por año, cuenta con más de 38.000 estudiantes en carreras de grado que se distribuyen en 12 sedes y recintos y 3.048 estudiantes de posgrado. Ofrece 240 opciones académicas, 246 programas de posgrado (especialidades 17; maestría profesional 87; maestría académica 78 y doctorados 10), cuenta con 5.098 docentes, posee más de 302 convenios internacionales con universidades de gran prestigio en el ámbito internacional, 260 estudiantes becados de posgrado que realizan estudios en el exterior, 214 visitantes académicos y académicas, 267 estudiantes internacionales, 1.814 proyectos, programas y actividades de investigación vigentes, entre otros.

El presente artículo tiene como objetivo proponer una definición del proceso de internacionalización de la UCR y describir el modelo que ha seguido desde sus orígenes hasta la actualidad, para lo cual se examinan diferentes definiciones y características de modelos de internacionalización, referentes en la educación superior.

\section{Conceptos afines a la Internacionalización de la educación superior}

Desde la Edad Media hasta avanzado el siglo XX, las relaciones internacionales entre las universidades se desarrollan como parte de la orientación universal de estas. Son las élites académicas de las universidades europeas las que primero tienen la posibilidad de realizar movilidades. Estas relaciones permiten ampliar la influencia de los países centrales a aquellos periféricos, de manera que cumplen propósitos ideológicos (Gacel-Ávila, 2000).

En las primeras décadas del siglo XX, las actividades internacionales de las instituciones son de carácter aislado y responden a necesidades institucionales de creación de programas de estudio e intereses de formación individualizada por parte de las personas que realizan un entrenamiento o misión en el extranjero. No existen en esta época las facilidades de movilidad y contactos que facilitaran una mayor interacción ni un concepto desarrollado de internacionalización como objeto de estudio.

Para la segunda mitad del siglo XX, particularmente después de la Segunda Guerra Mundial, las actividades de internacionalización de las instituciones universitarias estuvieron muy ligadas a visitas espontáneas de docentes y estudiantes del extranjero, becas de estudio en el exterior, intercambio de materiales académicos, y a las posibilidades que ofrecían los organismos de cooperación internacional. De esta manera, la participación de las universidades en actividades internacionales no necesariamente estaba vinculada con las prioridades de carácter institucional, ni demandó un papel activo por parte de estas, sino que estuvo basada en las ofertas de cooperación e intereses de los países de los organismos cooperantes e iniciativas espontáneas del personal académico o de estudiantes que realizaron movilidades al exterior para ampliar conocimientos.

En la década de los ochenta, especialmente en Latinoamérica, se da una fuerte disminución de oportunidades de cooperación internacional, a raíz de la crisis fiscal de las universidades 
públicas (tabla 1). Esto, sin duda, tuvo efectos poco positivos en la educación superior, ya que los recursos disminuyeron y los costos de estudio en el exterior se incrementaron.

Tabla 1

Cambios asociados a la evolución del concepto y el accionar institucional de la internacionalización de la educación superior, en las últimas décadas

\begin{tabular}{|c|c|c|}
\hline Ochentas & Noventas & Dos mil en adelante \\
\hline $\begin{array}{l}\text { Internacionalización centrada } \\
\text { en actividades de carácter ins- } \\
\text { titucional, de tipo receptiva de } \\
\text { oportunidades provenientes del } \\
\text { exterior más que enfocada en una } \\
\text { política proactiva. }\end{array}$ & $\begin{array}{l}\text { Internacionalización como un proce- } \\
\text { so de transformación que trasciende } \\
\text { el ámbito institucional y se convierte } \\
\text { en eje transversal de la acción subs- } \\
\text { tantiva institucional. } \\
\text { Posee una variedad de componentes y } \\
\text { actividades internacionales de movi- } \\
\text { lidad: académica y estudiantil el flujo } \\
\text { de nuevos conocimientos que incorpo- } \\
\text { ra la dimensión internacional del cu- } \\
\text { rrículo y métodos de enseñanza; así } \\
\text { como, a la gestión de estos procesos, } \\
\text { apoyados con políticas y compromi- } \\
\text { sos claros, y la creación de oficinas de } \\
\text { apoyo a los servicios orientados hacia } \\
\text { las actividades internacionales. }\end{array}$ & $\begin{array}{l}\text { Internacionalización convertida } \\
\text { en un requisito indispensable, se } \\
\text { ha diversficado y las actividades } \\
\text { e iniciativas que promueve han } \\
\text { cambiado de acuerdo con las trans- } \\
\text { formaciones del contexto institu- } \\
\text { cional, regional e internacional. } \\
\text { Estos cambios en el concepto pro- } \\
\text { mueven un ámbito de reflexión y } \\
\text { evaluación acerca de los alcan- } \\
\text { ces, productos e impactos que se } \\
\text { están generando. }\end{array}$ \\
\hline
\end{tabular}

Nota: Elaboración propia.

El proceso de internacionalización en las universidades se concibió mayormente a nivel institucional, no existió como objeto específico de estudio, tampoco provocaba debates ni reflexiones especializadas y mucho menos se pensaba en hacer inversión pública hasta los noventa (Didou-Aupetit, 2007).

Para los noventa se incluyen nuevos componentes, tales como el flujo de conocimiento, por medio del intercambio académico y algunas modificaciones en el contenido del currículo, en los métodos de enseñanza, y en el nivel organizacional, así como la influencia de la globalización en estos, acentuando su complejidad (tabla 1). Varios sujetos expertos en el tema de la internacionalización de la educación superior contribuyen con sus definiciones a denotar que, en lugar de ser un proceso estable y fijo, este concepto se enmarca en un contexto de gran fluidez y dinamismo y, por ende, sus características no son estáticas, sino más bien varían de acuerdo con el contexto global, nacional e institucional en el que se desarrolla la educación superior.

Para Arum y Van de Water (1992, citado por Knight, 2005), la internacionalización se refiere a "las múltiples actividades, programas y servicios que caen dentro de los estudios internacionales, intercambio educativo, internacional y cooperación técnica" (p. 202).

En 1994, Jane Knight (citado por Knight, 2005, p. 7) concluye que la internacionalización conlleva “... un proceso de integrar una dimensión internacional e intercultural a las funciones de enseñanza, investigación y servicio de la institución”. 
Van der Wende (1996, citado por Gacel-Ávila, 2009, p. 7) define la internacionalización desde dos niveles: uno global y otro institucional: el primer nivel se refiere a: “... todo aquel esfuerzo hecho por el sistema de educación superior para responder a los requerimientos y retos planteados por la globalización de las sociedades, la economía y los mercados de trabajo", mientras que en el segundo nivel se centra en: “... el proceso de desarrollo del currículo y de innovación curricular que tiene como meta integrar la dimensión internacional en el contenido del currículo y, si es relevante, también en el mismo método de enseñanza".

En el caso de Ellingboe (1996, citado por Gacel-Ávila, 2009, p. 7) relaciona la internacionalización con la mejora en la calidad de la educación superior y con:

Una visión en proceso orientada al futuro, multidimensional, interdisciplinaria, que requiere de fuerte liderazgo e involucra múltiples actores que trabajan en pro del cambio de dinámica interna en una institución, con la finalidad de responder y adaptarse de manera apropiada a un contexto externo crecientemente diverso, globalizado y en perpetuo cambio.

Rudzki (1998, p. 16) concibe la internacionalización como: “... promotora de la excelencia en las funciones universitarias” y Schöormann (1999, citado en Gacel-Ávila, 2009, p. 6) define la internacionalización a modo de:

Un proceso continuo, comprehensivo y contra-hegemónico que ocurre en el contexto internacional del conocimiento en el que las sociedades son vistas como subsistemas de un mundo más amplio e inclusivo. El proceso de internacionalización de las instituciones de educación superior remite a un programa de acción comprehensivo y multifacético, que se debe integrar en todos los aspectos del sistema educativo universitario.

De esta manera, en la década de los noventa la internacionalización de la educación superior se consolida como un objeto de estudio y se reconoce como un arduo proceso que no solo se desarrolla en el ámbito institucional, sino que además (tabla 1) trasciende a un espacio externo diverso. Se convierte en un proceso estratégico para las universidades, integrándose a las actividades sustantivas para la mejora de la calidad de la educación, su pertinencia y las competencias de las futuras generaciones de profesionales en un mundo cada vez más globalizado.

Para el periodo del año 2000 en adelante, De Wit (2001, citado por Gacel-Ávila, 2009, p. 6) define la internacionalización como “... una ampliación del término educación internacional y un proceso estratégico cuya meta es la integración de la dimensión o perspectiva internacional e intercultural en las funciones sustantivas"

En forma análoga, Knight concibe la internacionalización como el “... proceso de integrar una dimensión internacional intercultural o global en las funciones y servicios de la enseñanza postsecundaria, a nivel nacional, sectorial e institucional" (Knight, 2005, p. 12). Para ella, este tipo de definición describe un fenómeno de carácter universal, cuyos propósitos y resultados van a depender de la parte interesada. En ese mismo año, Jesús Sebastián (citado por Gacel-Ávila, 2009, p. 8) precisa que la internacionalización es: 
Un proceso cultural al interior de la universidad, que no supone una pérdida de la identidad institucional, sino un medio para su fortalecimiento en un espacio de interacciones más amplio. La internacionalización contribuye al fortalecimiento institucional y a un mejor cumplimiento de sus objetivos, a través de la mejora de la calidad, la pertinencia y las competencias.

Mientras que Gacel-Ávila (2009) se refiere a la internacionalización como:

Un proceso educativo que integra en las funciones sustantivas universitarias una dimensión global, internacional, intercultural, comparada e interdisciplinaria, que pretende proporcionar en los estudiantes una perspectiva global de las problemáticas humanas y una conciencia global en pro de los valores y las actitudes de una ciudadanía global responsable, humanista y solidaria. (pp. 7-8)

Para esta misma autora, además, la internacionalización es:

Un proceso de renovación institucional que pretende incorporar una dimensión internacional e intercultural en la cultura, misión, visión y transversalmente en todas las estrategias institucionales para el fortalecimiento institucional, el mejoramiento de la calidad y pertinencia del perfil de egresados, de los programas docentes y de los productos de la investigación. (Gacel-Ávila, 2009, p. 8)

A partir de esta primera década del siglo XXI, la internacionalización de la educación superior integra un cambio en la cultura institucional de las universidades a nivel nacional e internacional, con diferentes propósitos y nuevas perspectivas en los procesos de enseñanza- aprendizaje.

De esta manera, las instituciones de educación superior utilizan diversas estrategias para desarrollar su propio proceso de internacionalización, en ese caminar, se percibe cómo influyen aspectos relacionados con la cultura institucional, las características del país en el que se insertan y el entorno internacional de la educación superior.

\section{Evolución del modelo de Internacionalización de la educación superior}

Como parte de los avances en el tema de la internacionalización de la educación superior, de acuerdo con las tendencias que se han seguido y las particularidades de las universidades, diversos estudios han desarrollado modelos que contribuyen a su análisis desde diversos ámbitos, tanto a nivel de estructura institucional como externo para su realización, de los cuales se proponen los siguientes:

\section{Modelo de internacionalización de Jane Knight (1994)}

Jane Knight presenta un modelo genérico de la internacionalización de la educación superior. Para el análisis de la internacionalización ella utiliza un método de abajo-arriba (institucional) y uno de arriba-abajo (nacional/sectorial) que estudia la relación dinámica entre los dos niveles (figura 1). 
Para Knight, la internacionalización es un ciclo determinado por las siguientes fases:

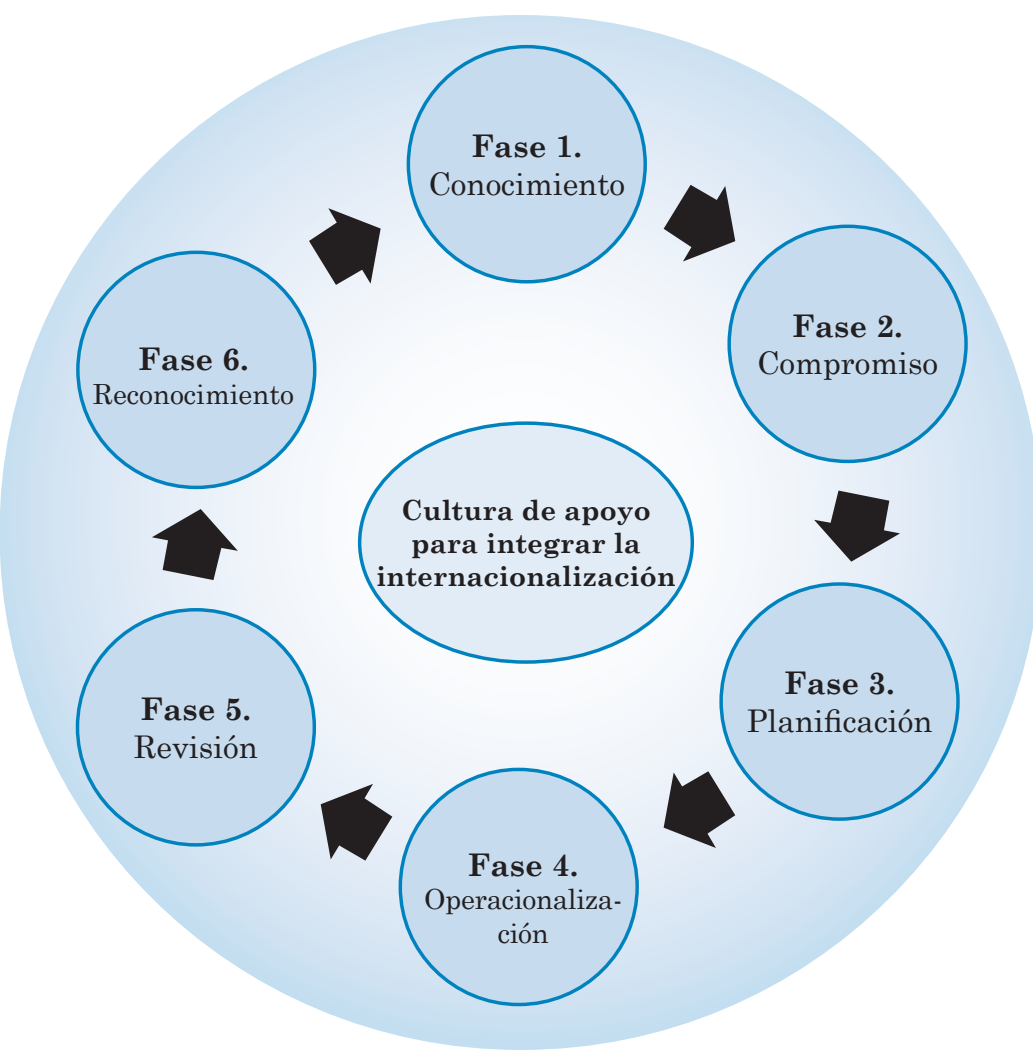

Fase 1. Conocimiento: de la necesidad, propósito y beneficios de la internacionalización para estudiantes, personal funcionario y profesorado.

Fase 2. Compromiso: de la administración superior, consejo de gobierno, profesorado, personal funcionario y estudiantes.

Fase 3. Planificación: identificar necesidades y propósitos de los recursos, objetivos, prioridades y estrategias.

Fase 4. Operacionalización: actividades académicas y servicios, factores organizacionales y uso de principios de guía.

Fase 5. Revisión: evaluación y mejoramiento de la calidad y el impacto de iniciativas y progreso de la estrategia.

Fase 6. Reconocimiento: desarrollar iniciativas de reconocimiento y recompensa para promover la participación de personal docente, personal funcionario y estudiantes.

Figura 1. Fases del modelo genérico Knight (1994) en la internacionalización de la educación superior. Elaboración propia con base en Knight (1994, p.12).

Las fases para el modelo Knight se consideran secuenciales, aunque no necesariamente. Este modelo implica una fase importante de concientización institucional acerca de la importancia de la internacionalización en el fortalecimiento de las actividades sustantivas de la universidad. El conocimiento debe desarrollarse tanto en las más altas jerarquías institucionales como en el resto de la comunidad universitaria: estudiantes, profesorado y personal administrativo. El compromiso institucional del más alto nivel y el compromiso por parte del resto de la comunidad universitaria son fundamentales para que este ciclo se lleve a cabo con el soporte requerido.

Para la fase tres de planificación de este modelo, se necesita proyectar las actividades para un mejor aprovechamiento de los recursos que son cada vez más limitados y, en la fase operativa, se requieren la apertura de oficinas de relaciones internacionales, asignar recursos humanos con las competencias técnicas necesarias para llevar a cabo la gestión de las actividades internacionales, así como docentes y estudiantes que puedan beneficiarse de las oportunidades de formación y movilidad internacional. El proceso de internacionalización está sujeto a diversos y constantes cambios, por lo que este modelo también incluye una fase 
cinco de revisión de las actividades y gestiones desarrolladas, las cuales deben estar ligadas a una estrategia institucional de reconocimiento (fase 6), en un contexto dinámico, en el que debe prevalecer el fortalecimiento y la calidad de la educación superior.

\section{Modelo de internacionalización de John L. Davies (1995)}

John L. Davies (1995) desarrolla un modelo basado en los factores que inciden en las estrategias de internacionalización de las instituciones de educación superior, los cuales son de índole interna y externa (figura 2).

Dentro de los factores internos que afectan la internacionalización de la educación superior, para este autor, se encuentran: (1) La misión institucional, tradiciones, y autoimagen. (2) La evaluación de las fortalezas y debilidades en los programas, personal y financiamiento. (3) Estructura de liderazgo organizacional. Y, para los factores externos que ejercen influencia en el proceso se tienen: (1) Percepciones externas de la imagen e identidad. (2) Evaluación de las tendencias y oportunidades en el mercado laboral internacional. (3) Evaluación de la situación competitiva.

Según Davies, en este modelo interactúan las actividades que desarrollan las mismas instituciones y la influencia que ejercen tanto factores internos como a nivel externo para su realización, las estrategias que aplican a las universidades abarcan los siguientes enfoques:

1. Ad hoc-marginal: Se refiere a aquellos casos en los que las actividades desarrolladas son pocas y no responden necesariamente a la misión o políticas claras a nivel institucional.

2. Sistémico-marginal: Implica poca cantidad de actividades, pero mejor organizadas a nivel de toda la universidad.

3. Ad hoc- centralizada: Involucra un mayor número de actividades, pero estas carecen de claridad conceptual.

4. Sistémico-centralizada: Incluye un importante número de actividades internacionales, organizadas en diferentes categorías, de manera coherente y coordinada.

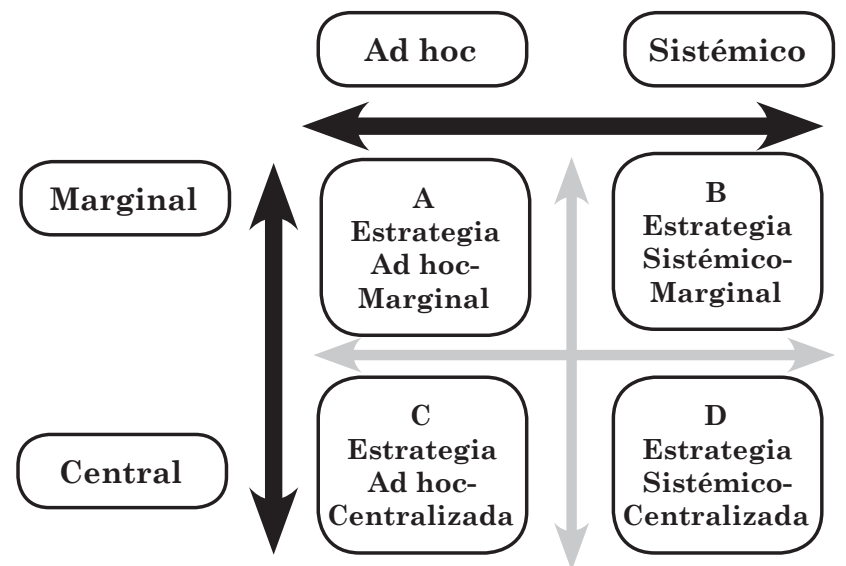

Figura 2. Modelo J. L. Davies (1995), basado en factores que inciden en las estrategias de internacionalización de las instituciones de educación superior. Elaboración propia a partir de Davies (1995, p. 16). 
El enfoque marginal ejemplifica lo que sucede en instituciones de educación superior que no cuentan con la experiencia ni los recursos técnicos y financieros para una mejor y mayor implementación de actividades de carácter internacional, por lo que estas ocurren por iniciativas individuales, sin más guía que el interés personal, por lo que no responden, necesariamente, a políticas o programas operativos institucionales para atender necesidades de la universidad o a estrategias de fortalecimiento a largo plazo de la actividad docente o de investigación.

Por otro lado, cuando la internacionalización se ha convertido en un eje transversal a las actividades que desarrollan los distintos ámbitos de la universidad, estas responden a estrategias fundamentadas en mejorar la gestión, la docencia, la investigación y la extensión que se desarrolla institucionalmente, y se cuenta con una organización que acompaña los compromisos del más alto nivel, con los recursos técnicos y financieros requeridos, por cuanto se traslada a un modelo centralizado.

\section{Modelo de internacionalización de Jocelyne Gacel-Ávila (2009)}

Para Gacel-Ávila (2009) el proceso de internacionalización es “... comprehensivo e implica integrar la dimensión internacional, intercultural y global en todas las políticas y programas institucionales para que las actividades internacionales logren ocupar un lugar prioritario en el desarrollo institucional" (p. 8).

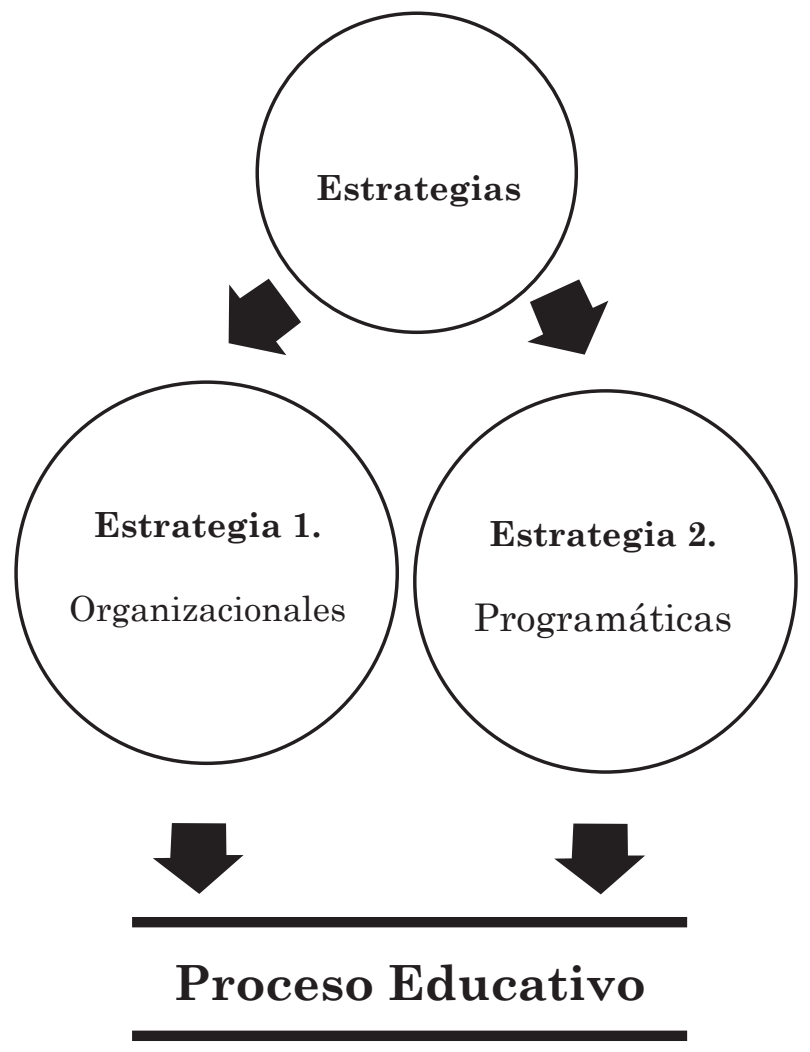

Figura 3. Modelo de Jocelyne Gacel-Ávila (2009) sobre el proceso de internacionalización de la educación superior. Elaboración propia a partir de Gacel-Ávila (2009, pp. 10-11). 
Siguiendo esta conceptualización y con base en estudios de la Organización para la Cooperación y el Desarrollo Económicos, Gacel-Ávila plantea un modelo de internacionalización sencillo que implementa dos tipos de estrategias (figura 3) que ejercen influencia en diferentes niveles del proceso educativo.

En este modelo las estrategias pueden ser organizacionales y programáticas y tienen su efecto en varios niveles del proceso educativo, a saber: (1) Micro- proceso enseñanza-aprendizaje en el aula. (2) Mediano- factores que determinan el contenido y métodos de enseñanzaaprendizaje, es decir, el currículo. (3) Macro- definición de estrategias y políticas institucionales.

Gacel-Ávila (2009) menciona que:

... las estrategias organizacionales tienen como objetivo la integración y la institucionalización de la dimensión internacional e intercultural en la misión, las políticas generales, así como en los sistemas y procedimientos administrativos institucionales. (p.10)

Dentro de la estrategia 1, en las actividades organizacionales de este modelo se sugieren:

1. Políticas y normatividad institucionales

2. Sistemas y procedimientos para la operación e implementación

3. Servicios de apoyo

4. Desarrollo de recursos humanos

En cuanto a la estrategia 2, la misma autora se refiere, a que “... las estrategias programáticas se refieren a las iniciativas que impactan directamente las actividades de naturaleza académica. Son programas institucionales destinados a internacionalizar la docencia, la investigación y la extensión" (Gacel-Ávila 2009, p. 11).

Como parte de las estrategias programáticas Gacel-Ávila (2009) plantea las siguientes:

1. Internacionalización del currículo: contenido y forma de los programas de curso; perfil y experiencia docentes; y fomento a la movilidad y el intercambio estudiantil.

2. Internacionalización de la investigación: integración de una perspectiva internacional, intercultural, interdisciplinaria y comparativa en los temas de investigación; el perfil y la experiencia internacional del personal de investigación; proyectos de investigación y publicaciones en colaboración con instituciones extranjeras; organización de seminarios y conferencias internacionales sobre temas de investigación relevantes; programas de movilidad para investigadores e investigadoras y estudiantes de posgrado.

3. Internacionalización de la extensión: organización de eventos culturales internacionales; inclusión de contenidos internacionales en los programas de radio y televisión de la institución; proyectos comunitarios con enfoque internacional; y centros especializados en la enseñanza del español y cultura del país.

4. Internacionalización de las actividades extracurriculares: actividades como viajes académicos internacionales para estudiantes, que aunque no sean parte del currículo, 
resulten efectivos para internacionalizar la experiencia educativa de estudiantes locales e internacionales.

El modelo propuesto por Gacel-Ávila se desarrolla para finales de la primera década de los años 2000. En este período existe un mayor conocimiento de la importancia de la internacionalización en el desarrollo de las instituciones de educación superior. Este modelo de internacionalización requiere una base sólida de apoyo institucional del más alto nivel y de organización, así como diversidad de estrategias para llevarlo adelante.

A diferencia de los modelos descritos previamente, el de Gacel-Ávila incluye un componente que para esta década cobra gran trascendencia, como lo es la internacionalización del currículo, pero al igual que los anteriores tiene un fuerte componente institucional.

\section{Modelo de internacionalización de Hans de Wit (2011)}

Hans de Wit (2002) basa su modelo de internacionalización en un ciclo, que articula nueve pasos con tendencia a centrarse en la dimensión institucional durante el proceso (figura 4), por lo que plantea una nueva versión basada en la internacionalización que presentara Knight (1994), en la que incluye otros componentes tales como la docencia, investigación, servicios, entre otros.

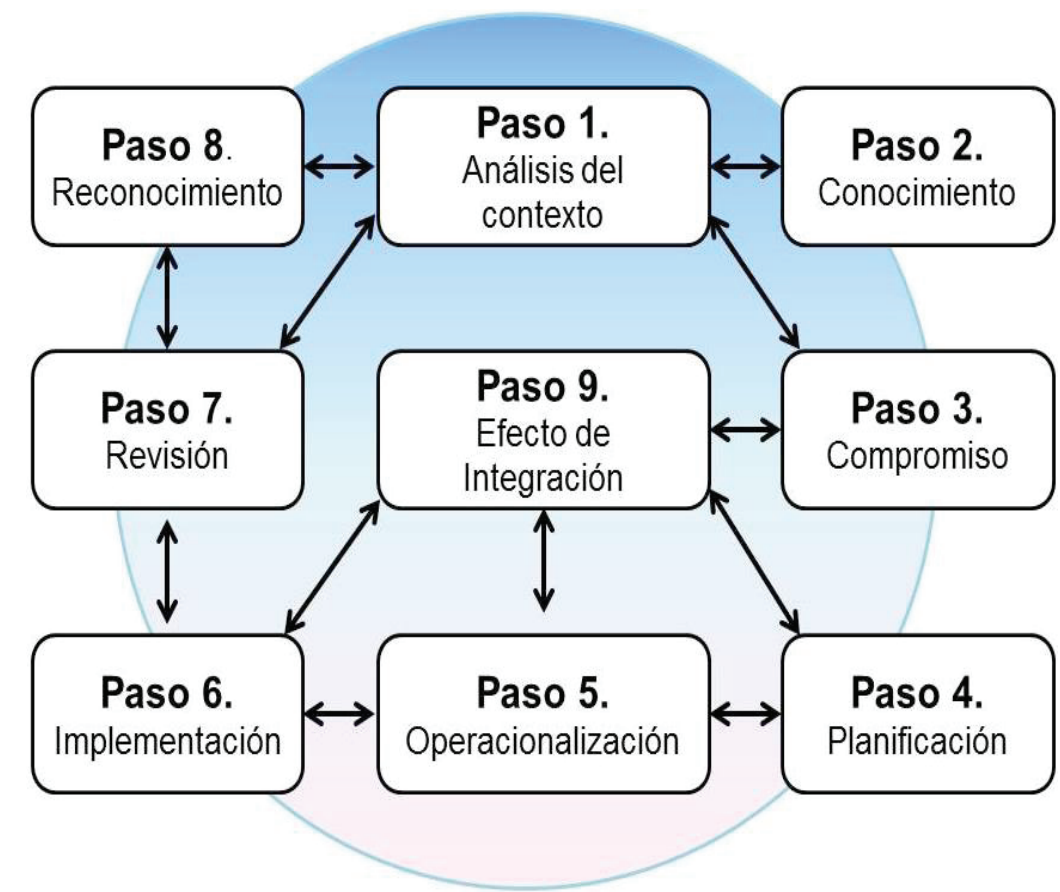

Figura 4. Modelo de Hans de Wit para la Internacionalización de la educación superior, visualizado como un proceso en pasos articulados que constituyen un ciclo.

Nota: Traducción libre hecha por las autoras para este artículo a partir del círculo de la Internacionalización, versión modificada, a partir de Hans de Wit (2002). 
Los distintos pasos de este modelo para De Wit implican lo siguiente:

Paso 1, Análisis del contexto: se realiza tanto interno como externo, en documentos sobre políticas y declaraciones.

Paso 2, Conocimiento: sobrelas condiciones, propósitosy beneficios delainternacionalización para estudiantes, personal administrativo, docente y de investigación, y sociedad en general.

Paso 3. Compromiso: se refiere a las autoridades de alto nivel administrativo, consejo universitario, personal docente, investigador y administrativo, y estudiantes.

Paso 4. Planificación: hace relación a las necesidades y recursos, propósito y objetivos, prioridades y estrategias.

Paso 5. Operacionalización: respecto a las actividades académicas y servicios, factores organizacionales.

Paso 6. Implementación: representa los programas y estrategias organizacionales.

Paso 7. Revisión: hace énfasis en la evaluación y mejoramiento de la calidad e impacto de las iniciativas y progreso de la estrategia.

Paso 8. Reconocimiento: valorar, dar estímulo y desarrollo de incentivos para el personal docente e investigador, administrativo y estudiantil.

Paso 9. Efecto de Integración: asegurar el impacto de las acciones en la enseñanza, la investigación y el funcionamiento de los servicios.

El modelo propuesto por De Wit (2002), al ser el más reciente, complementa el de Knight (1994) con tres pasos adicionales que responden a los cambios en la dinámica de la actividad internacional de las universidades y la influencia de diversos actores internacionales en su desarrollo. Este modelo propone la necesidad de hacer un análisis del contexto, ya que, además del plano institucional, el accionar internacional de las universidades en la actualidad está influenciado por la globalización de la educación superior.

Asimismo, deben tomar en cuenta las políticas y estrategias planteadas por espacios de reflexión, tales como las Cumbres Presidenciales, Conferencias Mundiales y Regionales de la Educación Superior, propuestas planteadas por Redes y Asociaciones de Educación Superior Regionales y Mundiales, entre otras.

De igual manera, las universidades cada vez más desarrollan un papel proactivo en sus procesos de internacionalización, por lo que De Wit incluye en su modelo el paso 6 de implementación, que reflejará el grado de compromiso, avance, experiencia, identidad, entre otras características propias del contexto para cada universidad.

Este modelo contempla, más allá de las actividades internacionales realizadas, el impacto que generan en los ámbitos institucionales de la docencia, investigación, extensión y de la administración en general. Dado que en la actualidad no es suficiente que una universidad participe en una gran cantidad de actividades, sino en las que sean requeridas para fortalecer su papel como formadora de grupos profesionales idóneos para una sociedad que los requiere 
de tal manera que se asegure de la calidad de la educación que imparten y de los servicios que ofrecen, en función de su misión institucional.

\section{Definición de internacionalización en la Universidad de Costa Rica}

\section{Concepto de internacionalización}

En el caso de este estudio tomando en cuenta el conocimiento adquirido y el contexto actual de la UCR, se propone el siguiente concepto de internacionalización: La internacionalización es un proceso que integra la dimensión internacional, intercultural e interdisciplinaria en el desarrollo de las actividades sustantivas de la universidad para responder de manera dinámica a los cambios y desafíos que enfrenta esta en el cumplimiento de su misión y visión que hoy requieren del compromiso, participación e interrelación de diversos actores en el ámbito institucional, nacional, regional e internacional.

Esta definición es empleada para referirse al concepto de internacionalización como una herramienta que ha contribuido al logro de la misión y visión o aspiraciones de la Universidad de Costa Rica:

Misión:

La Universidad de Costa Rica es una institución de educación superior y cultura, autónoma constitucionalmente y democrática, constituida por una comunidad de profesores y profesoras, estudiantes, funcionarias y funcionarios administrativos, dedicada a la enseñanza, la investigación, la acción social, el estudio, la meditación, la creación artística y la difusión del conocimiento. (UCR, 2006, p. 1)

Aspiraciones:

- Fortalecer la excelencia académica mediante el desarrollo y el cultivo permanente de una cultura de calidad, con una articulación estrecha entre docencia, acción social e investigación y por medio de la actualización de los planes de estudio en grado y posgrado en todas sus sedes universitarias, la generación de carreras innovadoras, el mejoramiento continuo y la formación de alto nivel del personal académico y administrativo, con el fin de atender, de manera pertinente, las necesidades de la sociedad costarricense y potenciar su liderazgo en el desarrollo de la educación nacional.

- Potenciar la generación de conocimiento científico, tecnológico, sociocultural e innovador en todas las unidades de la Universidad, entre disciplinas, así como incorporarse a redes académicas internacionales, basadas en el reconocimiento recíproco, el respeto y los beneficios compartidos, con miras a fortalecer la cultura académica.

- Promover la integración, las alianzas, el compromiso social, la cooperación, la relación solidaria, la difusión del quehacer universitario y la innovación en aras de forjar nuevos espacios, con el fin de transferir e intercambiar el conocimiento generado entre la Universidad y la sociedad. 
- Promover la democratización del ingreso a la educación superior mediante programas que favorezcan la equidad y la inclusión social y, al mismo tiempo impulsar iniciativas para fortalecer los servicios de apoyo a la población estudiantil, con el fin de facilitar la permanencia y la culminación exitosa de sus estudios en la Institución.

- Impulsar la internacionalidad solidaria mediante el desarrollo de redes académicas y la movilidad de docentes, estudiantes y personal administrativo.

- Actualizar los mecanismos y las plataformas de la gestión universitaria velando por la sostenibilidad ambiental, el liderazgo tecnológico y la modernidad de la infraestructura física, para potenciar la pertinencia, eficiencia y rendición de cuentas. (UCR, 2013, p. 7)

\section{Modelo de internacionalización de la UCR}

Para efectos del presente estudio se ha dividido el modelo propuesto de internacionalización de la UCR en seis etapas (figura 5):

Etapa 1 Formación humanística y crecimiento institucional: Durante sus primeros años de funcionamiento, las primeras vinculaciones internacionales de la UCR se desarrollan en respuesta al interés de las autoridades universitarias así como de personal docente, investigativo y estudiantes.

Desde sus inicios, en los años cuarenta a la década del cincuenta, la UCR realiza pocas actividades a nivel internacional.

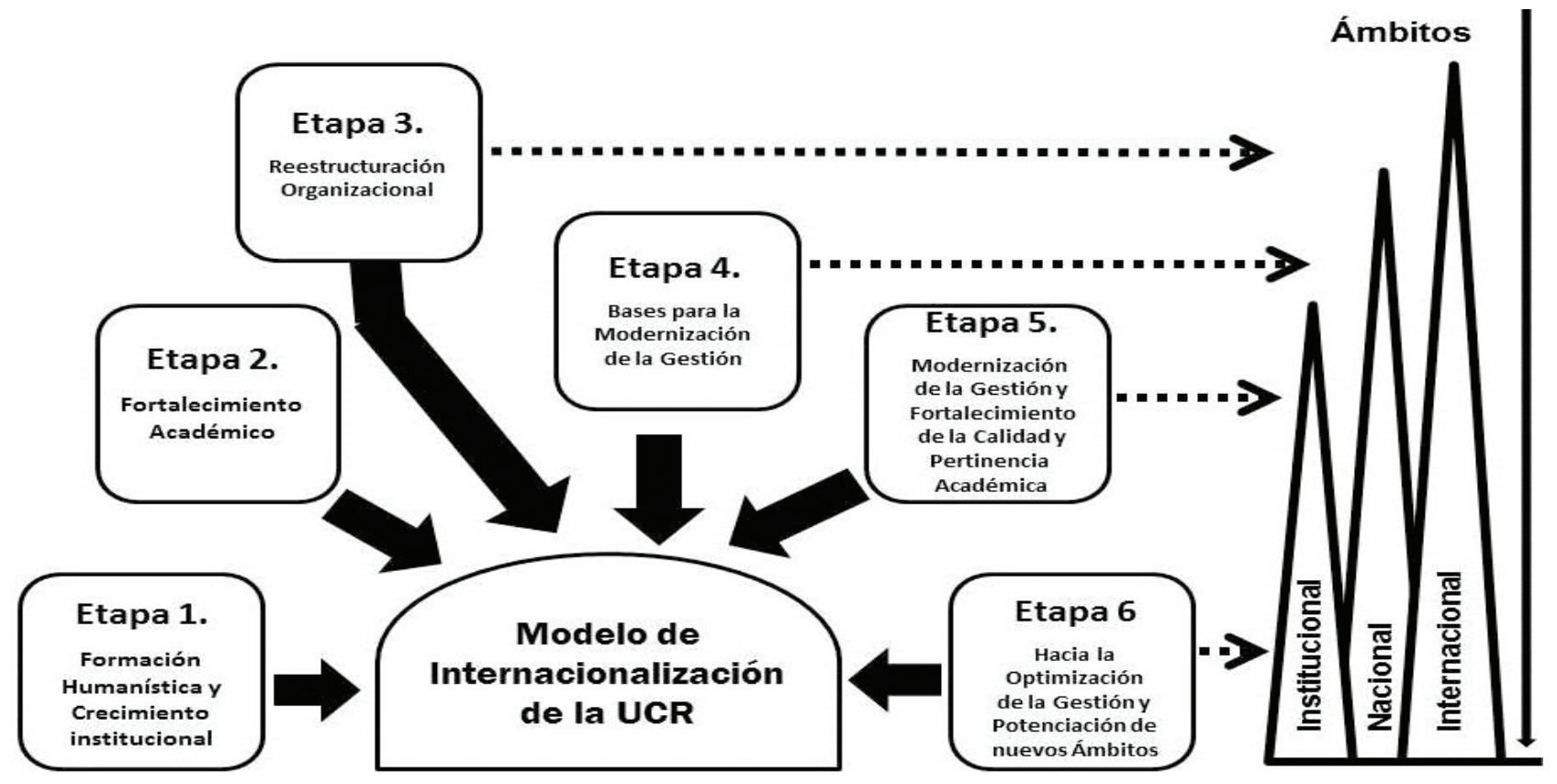

Figura 5. Etapas que definen la evolución del modelo de internacionalización en la UCR a lo largo del tiempo. Elaboración propia. 
Esta situación coloca a la UCR en el enfoque de carácter ad hoc-marginal, como lo define Davies (1995), determinado por intereses internos de la Institución como lo era el fortalecimiento de sus primeros programas de estudio y mejoramiento de la docencia, por medio de la visita de misiones de profesionales del extranjero para evaluar sus programas o bien para impartir clases; pero también motivado por el contexto externo, principalmente centroamericano, debido a su participación en actividades promovidas por el Consejo Superior Universitario Centroamericano (CSUCA) y colaboraciones que se desarrollaron estrechamente.

Asimismo, desde sus inicios en la UCR se identifican las dos primeras fases del ciclo de internacionalización del modelo de Knight (1994): (1) Conocimiento: Existe un conocimiento de las autoridades de los beneficios de estimular la participación del personal en actividades en el exterior, así como del aporte que docentes del extranjero pueden dar, al abarcar necesidades de formación con carácter universal en las primeras etapas de la UCR.

Durante este período fue clave el desarrollo de una facultad de humanidades, cuya creación involucró una activa participación de las autoridades de más alto nivel de la Institución, así como del sector educativo en Centroamérica. Es en este proceso en el que se empiezan a dar las primeras relaciones internacionales de la UCR con instituciones centro y suramericanas, estadounidenses y puertorriqueñas. En la fase 2 de compromiso: Las autoridades universitarias apoyan decididamente las posibilidades de formación en el exterior y desde la Secretaría que formaba parte de la Rectoría se colaboraba en los trámites generales relacionados con las movilidades al exterior de autoridades universitarias e invitaciones a profesorado extranjero, se identifican necesidades de formación, y se empiezan a realizar las primeras actividades de colaboración con universidades centro y suramericanas, del Caribe, europeas y estadounidenses para aprender de sus experiencias y facilitar colaboraciones académicas.

Desde sus orígenes en la década de los cuarenta, las máximas autoridades universitarias, con gran visión, reconocen la importancia de establecer relaciones con universidades en el exterior, de contar con profesorado de otros países como parte de su planta académica, así como de formar a sus docentes en universidades extranjeras. Este interés por la formación en el exterior se desarrolló gracias a que un grupo de docentes tuvo la oportunidad de estudiar en el extranjero en décadas anteriores a la creación de la UCR, como es el caso de Carlos Monge Alfaro, quien obtuvo el título de "Profesor de Estado" en Chile, junto con otros destacados intelectuales costarricenses, entre finales de los años veinte y principio de los treinta, como parte de una tercera generación que viajó a formarse en Chile (Dengo-Obregón, 2003).

Durante la segunda mitad de los años cuarenta, “... la Universidad tiene relaciones con otros centros de educación superior, por medio de los viajes realizados por algunos grupos universitarios de docentes a Tulane, Washington y Columbia, así como mediante reuniones y congresos centroamericanos" (Herrera-Zavaleta y Rodríguez-Molina, 1994, p. 62). Los mismos autores señalan que "a principios de la década de los cincuenta, Carlos Monge Alfaro viaja a Guatemala y El Salvador, a fin de trabajar de cerca con las universidades centroamericanas en la unificación de planes de estudio" (Herrera-Zavaleta y Rodríguez-Molina, 1994, p. 88).

En ese período, como lo expone Macaya-Trejos (1998), se da continuidad a una estrecha relación de cooperación que inició desde 1893 con la visita de Anastasio Alfaro, naturalista costarricense, al Museo de Historia Natural de la Universidad de Kansas y, luego, por parte 
del señor José Osma, profesor de español, quien en 1928 es nombrado cónsul honorario de Costa Rica en Kansas en 1928 y quien logra promover la visita de estudiantes costarricenses a la Universidad de Kansas y convertirles en el grupo extranjero de estudiantes más numeroso de esa universidad al término de la Primera Guerra Mundial.

Por su parte, durante los años cincuenta, Rodrigo Facio y Fabio Baudrit visitan la Universidad de Río Piedras, Puerto Rico, a fin de conocer su sistema organizacional. Asimismo, la "profesora Emma Gamboa obtuvo su título de 'Doctor en Filosofía', en la rama de Educación, en la Universidad del Estado de Ohio, Estados Unidos" (Dengo-Obregón, 2003, pp. 244-245).

Con miras a fortalecer la formación humanística en la Institución, Herrera-Zavaleta y Rodríguez-Molina (1994) mencionan que, en esa misma década, el rector, Rodrigo Facio, viaja a Europa para identificar docentes con interés en trabajar en la universidad impartiendo cursos en diversos departamentos. Para el rector Facio, aportarían "una inyección de cultura del exterior que sacudiría la inercia de nuestros profesores" (p. 99).

Macaya-Trejos (1998) afirma que, en este período, se llega a contar entre la planta docente de la UCR con docentes de la Universidad de Florida, así como con visitas académicas de personal de la Universidad de Puerto Rico. De igual manera se consolidan las relaciones de colaboración con la Universidad de Kansas, por medio de la visita del rector Rodrigo Facio en 1958 y la firma en 1959 de un Convenio de Colaboración entre ambas instituciones.

Para entonces, los intercambios con instituciones extranjeras también favorecen el desarrollo de otras áreas de la Universidad que necesitaban avanzar para emparejar el crecimiento institucional, como es el caso de mejoras en la infraestructura. Como plantean Herrera-Zavaleta y Rodríguez-Molina (1994), en seguimiento al estudio realizado por arquitectos universitarios, se promueve su visita a edificios y laboratorios de otras universidades y edifican la ciudad universitaria, siguiendo los modelos de instituciones de educación superior extranjeras, tales como las de Panamá, Colombia y Venezuela. Los mismos autores, en el mismo año, destacan el trabajo que la Universidad realiza para lograr otros vínculos y apoyo para expandir las oportunidades de estudio a otros países de Latinoamérica y Europa, en las palabras del entonces rector, don Rodrigo Facio, para "... balancear adecuadamente las influencias culturales provenientes del extranjero" (p. 150). Por lo tanto, en años venideros se estimulan nuevos lazos de cooperación con otros países, tales como: Francia, Japón, Alemania, y España.

Las vinculaciones internacionales que entabla durante sus inicios la UCR cobran gran importancia para el desarrollo de los nuevos programas de estudio, mejora de los métodos de enseñanza, y crecimiento de la infraestructura necesaria, con el fin de responder a los objetivos que se trazaron para la Institución.

Etapa 2: Fortalecimiento académico: Conforme avanza la década del sesenta, el modelo internacional de la UCR va tomando un enfoque sistémico-marginal tal cual lo sugiere Davies (1995) en su modelo, debido a que desarrolla acciones cada vez más organizadas a nivel de la Institución orientadas fuertemente a la formación de personal en el extranjero. En este período, la Universidad empieza a desarrollar las bases de la gestión que dará acompañamiento administrativo en el desarrollo de sus vinculaciones internacionales. Inicialmente, delega estas funciones en la instancia que se denominó Patronato de Becas. 
Mediante los avances que se van desarrollando en este período, se van implementando, según el modelo de Knight (1994), la tercera fase de "planificación" y la cuarta "operacionalización". Los avances se desarrollan tanto en el ámbito organizacional como en el contexto internacional. En la fase 3 de planificación: La UCR empieza a planificar sus actividades internacionales orientadas hacia procesos de movilidad académica, favorecidos por el apoyo de recursos institucionales y de programas de cooperación académica internacional que empiezan a surgir durante la época.

Para los años sesenta, como señala Araya (1991), se intensifican los programas de cooperación técnica por parte de instituciones de educación superior de Norteamérica, incluyendo fundaciones, organismos internacionales como la UNESCO, como parte de criterios de modernización universitaria en el marco de la Alianza para el Progreso y con miras a fortalecer la integración en Centroamérica en el ámbito económico y educacional. Por ejemplo, con estos apoyos se cuenta con las visitas de especialistas internacionales quienes se ocuparon de evaluar la calidad de las carreras y de los departamentos universitarios.

En la medida en que se estrechan estos vínculos también se da inicio a un plan de formación de personal universitario del área docente y administrativa. De esta forma, en la década del sesenta, la UCR inicia un programa que desde entonces será clave en su proceso de internacionalización, por medio de financiamiento con presupuesto universitario complementado con apoyo financiero de otras fuentes, principalmente de los Estados Unidos de América.

En la fase (4) de operacionalización, como señala Gómez-Redondo (1999), la UCR crea el Departamento de Becas al Exterior dentro del Patronato de Becas Estudiantiles, como dependencia de la Rectoría, a cargo del Lic. Gerardo Bogarín Benavides. Básicamente, su función estuvo concentrada en atender los trámites relacionados con la oferta de becas. Poco tiempo después de asumir su cargo, el Lic. Bogarín Benavides fue beneficiado con una beca de estudios de posgrado en Canadá y, en su lugar, fue nombrado temporalmente el señor Rodolfo Méndez Ulloa.

Para este periodo, la UCR vivía un ambiente renovador, que llevó al III Congreso Universitario, donde se lograron resultados que fueron transcendentales para el quehacer institucional, desarrollo científico y tecnológico, organizacional y de gestión universitaria (Gutiérrez, 1982).

De esta manera, en la década del setenta la Universidad inicia un nuevo ciclo en su proceso de internacionalización en el que se refleja, según el modelo de Knight (1994), la fase 5 de "revisión", donde durante el III Congreso Universitario en Asamblea Universitaria se realiza una evaluación de las necesidades de mejora en la organización de la Universidad. Se recomendó la urgente creación de las vicerrectorías de: Docencia, Investigación, Vida Estudiantil y Acción Social, asimismo, el establecimiento del Sistema de Estudios de Posgrado, el Trabajo Comunal Universitario y los Seminarios de Estudios Generales, lo cual conllevó a plantear diversos cambios de estructura docente y administrativa (Rodríguez-Vega, 1972).

En el Informe del Rector UCR para el periodo de 1971-1972, se registra que uno de los acuerdos establecidos durante el III Congreso Universitario que tuvo gran alcance para sentar las bases de la estructura que tendría a cargo el apoyo a la gestión y promoción de la participación institucional, en actividades de carácter internacional, fue la recomendación de crear una Oficina de Asuntos Internacionales (OAI), que tendría las siguientes funciones: (a) Colaborar con el rector en las relaciones de la Universidad con las instituciones y organismos 
internacionales; (b) Gestionar y tramitar los convenios internacionales, las ayudas financieras y de otra índole y, (c) Coordinar sus actividades internas con la Oficina de Planificación Universitaria y con las Vicerrectorías en lo que corresponda (Rodríguez-Vega, 1972, p. 20).

Esta recomendación fue visionaria y estratégica, ya que desde su tercera década de funcionamiento la UCR ya reconoce la necesidad y la importancia de establecer una estructura que colabore con la Rectoría en la organización y aprovechamiento de las oportunidades de carácter internacional y de los recursos de la cooperación académica internacional. Desde su creación se ubica en un segundo nivel jerárquico en el organigrama institucional, a cargo de la Rectoría, que le permitirá interactuar y coordinar estrechamente con las vicerrectorías recién creadas, así como con el resto de actores universitarios. De esta manera, la UCR se convierte en una de las primeras universidades centroamericanas en conformar una Oficina de Asuntos Internacionales.

El Informe del Rector UCR, correspondiente al periodo 1972-1973 (Rodríguez-Vega, 1973), del mismo modo enfatiza que las recomendaciones del III Congreso Universitario hicieron que la Universidad otorgara especial énfasis al papel que juegan los organismos internacionales para el beneficio y el progreso de la academia. En este período se legisló sobre las características de los intercambios y se proyectó que la formación del profesorado, investigadores e investigadoras y profesionales se diera en las más amplias y diversas instituciones en el mundo y, estas instituciones deberían ser las mejores en la rama de la especialidad, a fin de asegurar que, a quienes se les otorgara el beneficio de formación, regresaran al país con el más alto nivel. Además, se legisló sobre las características que debían tener los convenios o contratos con cualquier organismo internacional, universidad o gobierno extranjero.

Una de las disposiciones más importantes de las estrategias organizacionales de la UCR fue acompañar la creación de la OAI, de su primer Reglamento aprobado el 25 de abril de1977, así como del marco normativo del Programa de Becas para Formación en el Exterior de Profesorado y Administradores de la UCR, denominado "Régimen de Beneficios para el Mejoramiento Académico de los Profesores y Funcionarios en Servicio", ya que su enfoque inicial fue hacia el fortalecimiento de este Programa (UCR, 1979).

La OAI, al iniciar sus funciones, lo hace con la dirección del Lic. Rafael Alberto Zúñiga Tristán, quien fue uno de los fundadores de la Facultad de Economía de la UCR. En la primera década de su funcionamiento, estuvo concentrada en dar seguimiento a la formación de recurso humano en el exterior y en el trámite de convenios con universidades extranjeras, con una estrategia sistémico-marginal de Davies (1995), aún no se contaba con la organización idónea para favorecer un mejor desempeño de su gestión. El resto de funciones inherentes a una Oficina de Relaciones Internacionales se encontraban desconcentradas en otras instancias de la Universidad, tales como en las Vicerrectorías de Docencia e Investigación.

Etapa 3: Primera reestructuración organizacional: A finales de los años ochenta, se identifica la fase 5 de "revisión" sugerida en el modelo de Knight (1994), ya que se empiezan a implementar nuevas estrategias organizacionales que conllevan una articulación de las gestiones administrativas de apoyo a la gestión del proceso de internacionalización de la UCR.

Como se evidencia en documentación interna de la OAI acerca del proceso de la primera reestructuración (1988-1989) organizacional, algunos elementos determinantes fueron: 
El 13 de setiembre de 1988 se promulgaron a propuesta de la OAI las "Normas para la regulación de becas cortas" para satisfacer las demandas de aquellos profesores que pretenden realizar proyectos de investigación, asistir a cursos cortos, seminarios, etc... (Garita-Bonilla, 1989, p. 17)

En este mismo documento se hace referencia a una situación encontrada en relación con los convenios internacionales:

... no había un archivo único, no se tenía claro qué convenios estaban vigentes; no se tenía un panorama preciso de cuál era la orientación política de esos convenios, ni cuál era el impulso que se les estaba dando. . . . Se realizó un estudio y reordenamiento de los convenios por la Universidad de 1975 a mayo de 1988. . . (Garita-Bonilla, 1989, p. 19)

A finales de la década de los ochenta se realiza un importante debate acerca de las funciones de esta dependencia en el ámbito institucional, ya que se consideraba que aún no estaba desempeñando la totalidad de las funciones que se le habían asignado en el momento de su creación ni la misión fundamental de otorgar el apoyo requerido a la gestión universitaria y fortalecimiento académico (Universidad de Costa Rica, s. f.).

En razón de lo anterior, se llevó a cabo un proceso de reorganización de la Oficina e inventario de las acciones internacionales que desarrollaba la UCR al año 1988, con el fin de consolidar una organización interna que inicialmente permitiera un mejor manejo institucional de los recursos destinados para actividades internacionales y de aquellos provenientes de fuentes externas.

En 1989 se elabora una Guía para Formulación y Trámite de Convenios de Cooperación e Intercambio en la UCR, debido a que, para entonces, no se seguían los pasos adecuados en la gestión de los convenios. Se quería lograr un mejor aprovechamiento de estos, basándose en alcanzar prioridades institucionales y crear normativa que regulara sus compromisos, a fin de proteger la Universidad de cualquier perjuicio.

A partir del año 1992 se plantea una reestructuración de la OAI, a cargo de su siguiente director, el Dr. Manuel María Murillo Castro, enfocada en centralizar las funciones relacionadas con su ámbito de acción y conformar una estructura organizacional mejor preparada para atender las nuevas demandas que debía enfrentar la UCR en sus relaciones internacionales (Garita-Bonilla, 1992).

En esta etapa se cuenta con la colaboración de personas expertas en análisis administrativo de la Vicerrectoría de Administración y de la Contraloría Universitaria para modificar procedimientos y mejorar los procesos de gestión (Garita-Bonilla, 1996).

Se reestructura el Programa de Estudios en Costa Rica, encargado de las gestiones relacionadas con el intercambio estudiantil. Anteriormente, varias unidades estaban a cargo de las gestiones de apoyo relacionadas con el intercambio estudiantil, a partir de 1992 se integran en un solo programa con apoyo de las instancias que antes tenían esa responsabilidad. Se brinda al estudiantado, a partir de entonces, una sesión de orientación, asesoría académica antes del inicio de los cursos, durante el proceso de matrícula y para la ubicación de alojamiento. Igualmente, se amplía el ámbito de gestión de la Oficina en 1995 
con la creación del área de cooperación académica internacional y esta pasa a denominarse Oficina de Asuntos Internacionales y Cooperación Externa (OAICE), dado que existe un claro interés de ampliar sus funciones a la consecución de recursos externos (Gómez-Redondo, 1999; Garita-Bonilla, 1996, p. 21) y en 1998 se crea el Programa de Académicos Visitantes.

Del año 1995 al 2004, en la gestión del Dr. Murillo en la OAICE, se consolidan paulatinamente las capacidades de gestión del proceso de internacionalización, con la conformación de los siguientes programas: Formación de Recursos Humanos; Estudios en Costa Rica; Intercambio de Estudiantes Costarricenses; Cooperación Académica Internacional; Académicos Visitantes; Convenios, y Asuntos Contables y Financieros. De esta manera, se empieza a fortalecer la organización de la OAICE, con mayor personal para apoyar a la Dirección de la Oficina en la implementación de actividades a cargo de cada uno de estos programas. Por otro lado, se facilita a esta Oficina un nuevo espacio físico en el Edificio Administrativo A, al lado del Edificio de la Rectoría. Para este período, la mejor organización administrativa de las actividades internacionales de la UCR permite contar con información más detallada de estas, gracias al seguimiento de las actividades realizadas por cada uno de los Programas de la OAICE (Macaya-Trejos, 2004).

Estrategia organizacional en el ámbito institucional: A partir de este período, la OAICE trabaja de manera más estrecha con la Rectoría (figuras 5 y figura 6), Consejo Universitario, vicerrectorías, sedes, unidades académicas, oficina de Sistema de Estudios de Posgrado y centros e institutos de investigación, promoviendo el desarrollo de actividades internacionales de movilidad académica y estudiantil, así como de cooperación académica internacional e interuniversitaria en las que participa la Universidad.

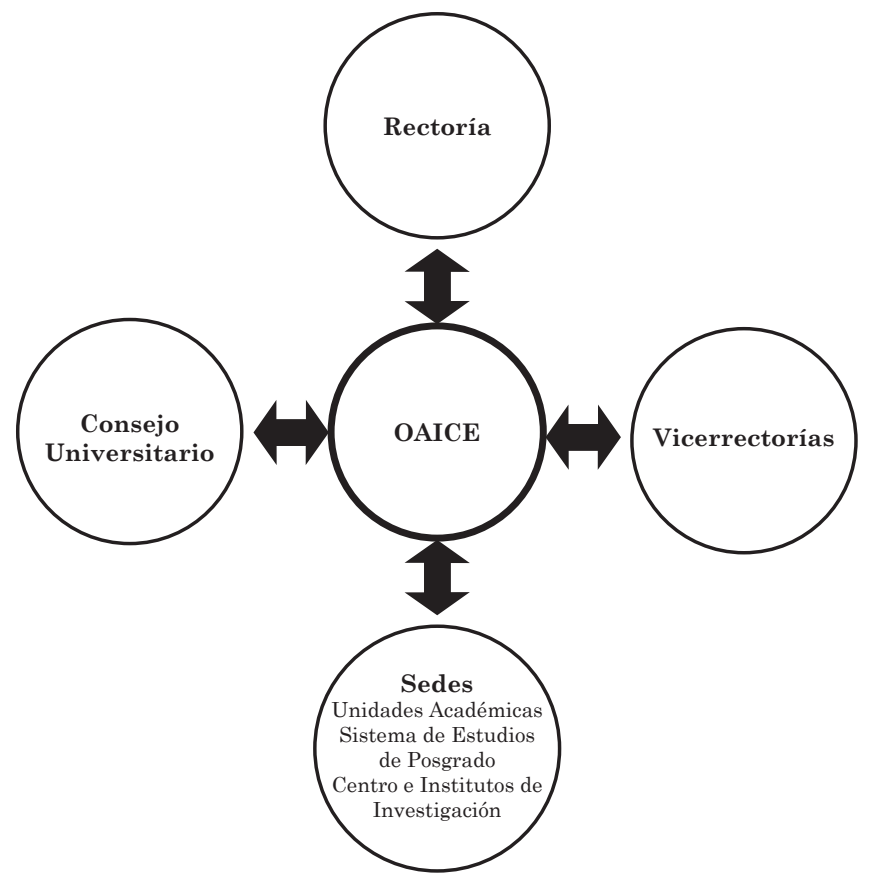

Figura 6. Estrategia organizacional de la internacionalización de la Oficina de Asuntos Internacionales y Cooperación Externa (OAICE) de la UCR en el ámbito institucional. Elaboración propia.

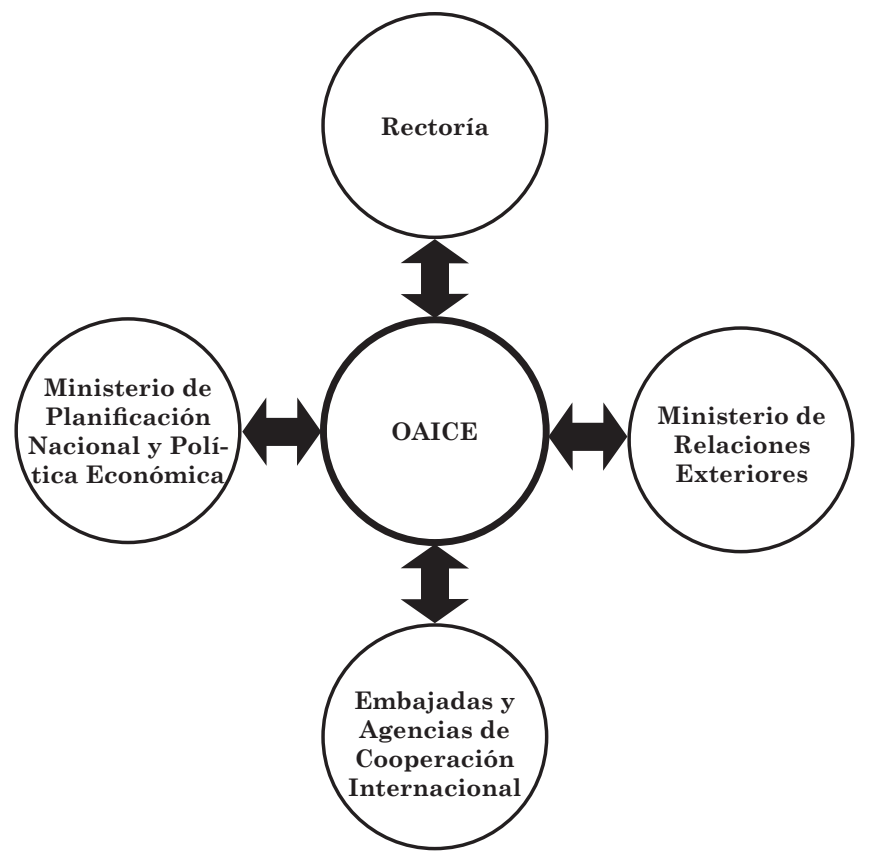

Figura 7. Estrategia organizacional de la internacionalización de la Oficina de Asuntos Internacionales y Cooperación Externa (OAICE) de la UCR en el ámbito nacional. Elaboración propia. 
Estrategia organizacional en el ámbito nacional: la OAICE se interrelaciona con el Ministerio de Planificación Nacional y Política Económica (figura 5 y figura 7) para la presentación de propuestas de solicitud de cooperación, así como el Ministerio de Relaciones Exteriores y Culto, que las canalizan ante las embajadas de los países extranjeros y las agencias de cooperación académica internacional.

Estrategia organizacional en el ámbito internacional: como parte del fortalecimiento de las estrategias organizacionales de la UCR (figura 5 y figura 8), durante la década de los años noventa y principios de la siguiente, se desarrollan políticas más claras (emitidas anualmente por el Consejo Universitario) en torno a actividades que promoverá la UCR en el plano internacional, tanto para la formación de la planta docente y administrativa, el vínculo con instituciones en el exterior mediante la firma de tratados, convenios y cartas de intención, así como para la participación en actividades internacionales que trascendieran favorablemente en áreas clave para la universidad.

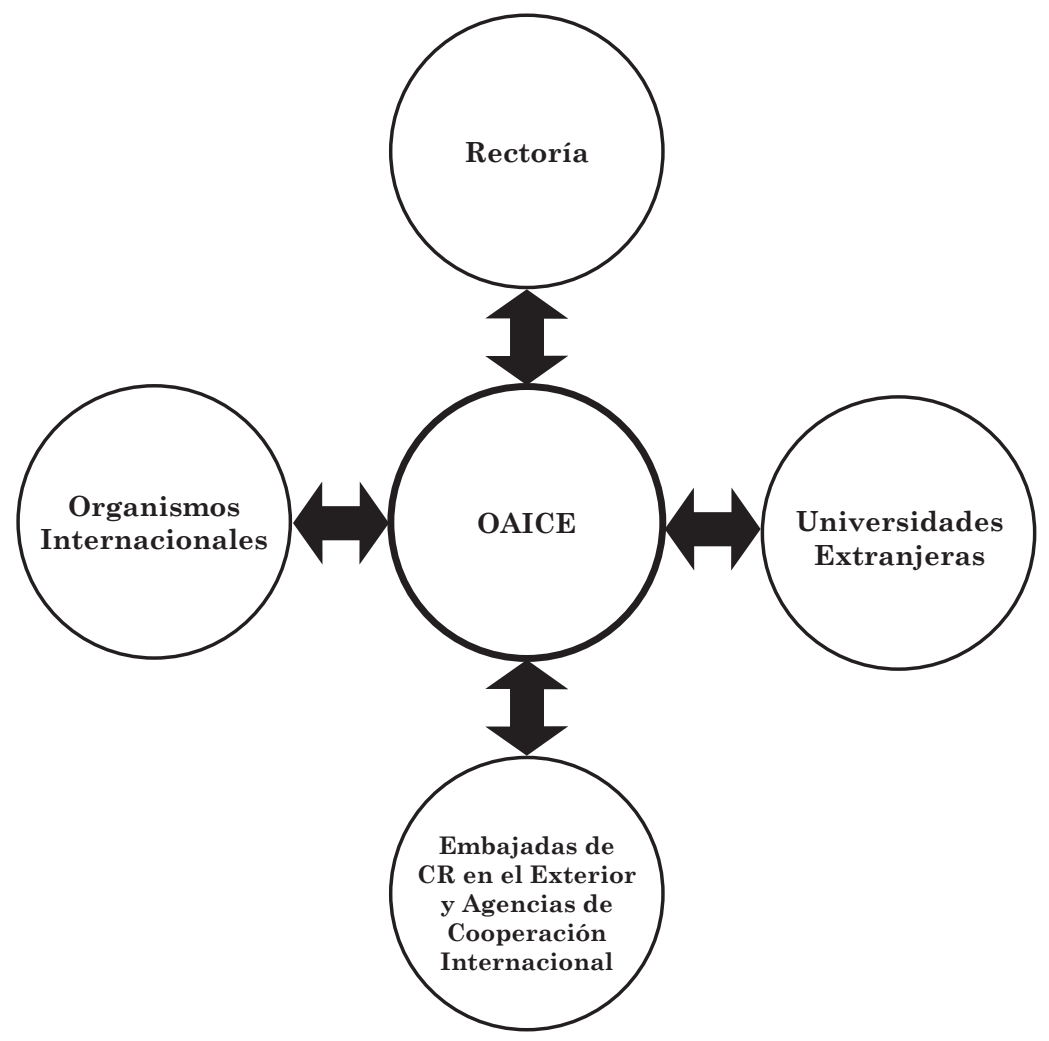

Figura 8. Estrategia organizacional de la internacionalización de la Oficina de Asuntos Internacionales y Cooperación Externa (OAICE) de la UCR en el ámbito internacional. Elaboración propia.

Según señala Gómez-Redondo (1999), con base en estas políticas de internacionalización se desarrollan mayores vínculos con instituciones en el exterior y participación en programas de cooperación, promovidos desde la OAICE, así como por iniciativas de las unidades académicas, de investigación, o de carácter individual, o bien de contrapartes internacionales. 
En razón del interés de las máximas autoridades universitarias para que la OAICE se dedicara más a la gestión de recursos, se da, durante esta etapa, prioridad a la suscripción de convenios y a la participación institucional en programas de cooperación académica internacional bilateral y multilateral, paralelamente al programa de formación de recursos humanos en el exterior y a la parte de movilidad estudiantil.

Cabe destacar que a partir de 1995, la OAICE promueve una de las participaciones más fuertes en esa época en proyectos de cooperación académica internacional tomando ventaja del Programa ALFA (América Latina Formación Académica) promovido por la Comisión Europea, dirigido a mejorar los procesos de gestión en las universidades latinoamericanas y, a la vez, a promover vínculos de colaboración académica con universidades europeas, gracias a una mejor integración de las capacidades de gestión y las fortalezas académicas con las que cuenta la Institución. Esta participación le genera una importante experiencia a la UCR tanto en el área de gestión como en la parte académica y favorece significativos contactos con universidades de prestigio internacional que redundarán en una mayor relación futura de cooperación.

De igual manera, durante este período, la OAICE, además de promover las becas de docentes en el exterior para estudios de posgrado y los intercambios estudiantiles y docentes, gestiona otros importantes proyectos de cooperación con Europa (Programa de Cooperación Francesa auspiciado por la Embajada de Francia, y el entonces, Centro Cultural y de Cooperación para América Central, el DAAD Servicio de Intercambio Académico Alemán, el Programa Intercampus de la Agencia Española de Cooperación Académica Internacional, el Programa de Becas Mutis, el Programa PIMA de Intercambio y Movilidad Académica), con Asia (Servicio de Voluntarios para el Extranjero de la Agencia de Cooperación Académica Internacional del Japón -JICA), América Latina (Programa Mexicano de Cooperación Académica Internacional para el Desarrollo, Programa Mesoamericano de Intercambio Académico ANUIES-CSUCA, Fondo Argentino de Cooperación, Programa del Centro Interuniversitario de Desarrollo -CINDA), Estados Unidos (Programa Fulbright-LASPAU) y con Canadá (Programa de la Organización de los Servicios Ejecutivos Canadienses -CESO).

Etapa 4: Bases para la modernización de la gestión: en esta cuarta etapa, entre la década del noventa e inicios de los años 2000, la UCR logra consolidar el enfoque de internacionalización sistémico-centralizada propuesto por Davies (1995), con el establecimiento de políticas de internacionalización anuales, en razón de un desarrollo mayor y mejor coordinado de la gestión de las actividades internacionales, con un importante respaldo institucional, y compromiso por parte de las unidades académicas. De igual manera, se establecieron en el año 2000, las "Normas Generales para la Firma de Convenios y Acuerdos con otras Instituciones".

De un modelo inicial más enfocado en su estrategia organizacional para mejorar los procesos institucionales, la UCR evoluciona hacia nuevas estrategias programáticas como las enunciadas por Gacel-Ávila (2009), en las que se privilegian las actividades internacionales orientadas al beneficio mutuo para el desarrollo del personal académico, administrativo y estudiantil de las instituciones participantes, con un impacto en sus programas académicos, la creación de nuevas competencias y conocimientos interculturales y en el desarrollo de una cultura institucional con perspectiva internacional. 
En esta etapa, tal como lo manifiesta el Informe de Gestión OAICE (Sittenfeld-Appel, 2012), la oficina se consolida como instancia de apoyo de la Rectoría, trabajando en estrecha coordinación con la Vicerrectoría de Docencia, Vicerrectoría de Investigación, el Sistema de Estudios de Posgrado y las unidades académicas de la Universidad en el desarrollo y consolidación de acciones tendientes al fortalecimiento de las políticas de internacionalización institucionales (González-García, 2012, pp.17-38).

Etapa 5: Segunda reestructuración: Modernización de la gestión y fortalecimiento de la calidad y pertinencia académica: A partir del 2005, ocurre una nueva reorganización de la OAICE, a cargo de la entonces directora Dra. Ana Sittenfeld Appel (Sittenfeld-Appel, 2012). Con el fin de modernizar la estructura organizacional de la gestión de las relaciones internacionales en la UCR, ese año se realiza un estudio donde se plantea una nueva estructura organizativa, encabezada por la Dirección y la Subdirección, y conformada por Secciones (figura 9), las cuales tienen la siguiente organización:

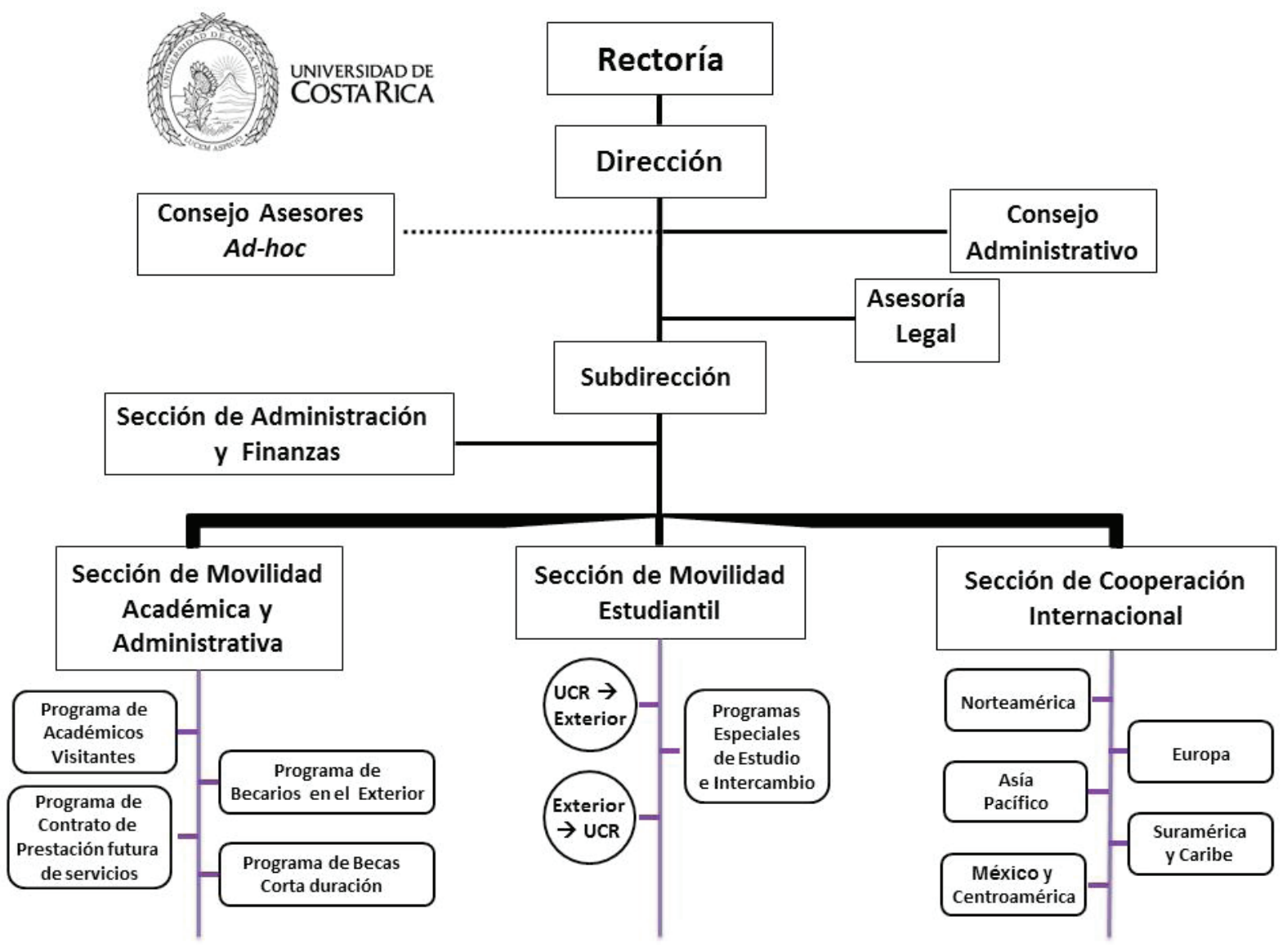

Figura 9. Organigrama de la OAICE de la UCR. Elaboración propia con base en Informes de Labores OAICE (2013-2014). 
Según se describe en los artículos del 6 al 12 del Reglamento de la Oficina de Asuntos Internacionales y Cooperación Externa, aprobado mediante Resolución de Rectoría N R-492011, el 05 de enero de 2011:

Art. 6: El Director es el superior jerárquico de la Oficina, Es un representante de la universidad ante las instituciones de educación superior extranjeras, organizaciones y organismos internacionales públicos o privados en asuntos propios de competencia de la Oficina. El subdirector es el funcionario de jerarquía inmediata al Director.

Art. 7: El Consejo Administrativo está conformado por la Dirección, Subdirección, Asesoría Legal y Jefaturas de las Secciones de gestión de la OAICE. Es la instancia que gestiona el plan de desarrollo estratégico y define las políticas administrativas de la gestión operativa de la OAICE; actúa como coordinadora entre las distintas secciones, así como con otras dependencias de la Institución, con el propósito de impulsar mecanismos eficientes y racionales en las competencias de la OAICE.

Art. 8: Recomienda, orienta y brinda servicios en esta materia a la Dirección y a las diferentes Secciones que componen la OAICE en la toma de decisiones, de acuerdo con las necesidades del momento.

Art. 9: Se encarga de facilitar la movilidad al exterior del personal docente y administrativo, con el propósito de lograr la formación de equipos humanos mejor capacitados en programas de alto nivel académico para el logro de los objetivos de la Universidad. Coadyuva en la movilidad, hacia la Universidad, de personal docente y administrativo, conforme a los principios institucionales de excelencia y calidad.

Art. 10: Facilita y coordina el proceso de movilidad internacional de estudiantes desde y hacia la Universidad de Costa Rica, de acuerdo con los principios de la internacionalización relativos a la difusión de los valores culturales y de las circunstancias nacionales de los países involucrados.

Art. 11: Coordina y fortalece la cooperación académica internacional, tanto bilateral como multilateral, mediante la gestión de convenios de colaboración con distintas instituciones de educación superior extranjeras. Asimismo, fomenta la participación institucional en los diferentes programas de cooperación auspiciados por las entidades nacionales o extranjeras involucradas en el proceso de internacionalización.

Art. 12: Asiste a la Dirección, Subdirección y a las demás Secciones de la Oficina en el desarrollo de labores de administración y finanzas. De este modo, supervisa, controla y ejecuta las labores administrativas y financieras que se derivan de la gestión integral.

Durante esta etapa de modernización de la OAICE, se amplía el número de personal que colabora en las diversas secciones, se garantiza la continuidad de varias funcionarias y funcionarios con trayectoria en la Oficina y se redistribuyen funciones. Se constituye un Consejo Administrativo conformado por la Dirección, Subdirección, Asesoría Legal y las Jefaturas de las Secciones mencionadas anteriormente, el cual tiene como propósito gestionar el plan de desarrollo estratégico y definir políticas administrativas de la gestión operativa de la Oficina. Se identifica la fase 4 de "Operacionalización" sugerida por Knight (1994) y orientada desde una estrategia sistémico-centralizada propuesta en el modelo de Davies (1995). 
En esta nueva administración se implementan diversas estrategias organizacionales que llevan a la OAICE a ser una de las Oficinas de Relaciones Internacionales mejor estructuradas y consolidadas a nivel nacional y regional.

En el 2006 se replantea el objetivo de los Programas Especiales de Estudio dirigidos a grupos de estudiantes de universidades en el exterior en diferentes épocas del año. Se empiezan a ofrecer cursos en diversas áreas impartidos en idioma inglés, combinados con cursos de idioma español como lengua extranjera y giras académicas de campo. Los recursos económicos generados por estos cursos son destinados para la creación de un fondo solidario que tendrá como fin apoyar a estudiantes de UCR para que cursen un semestre académico en instituciones extranjeras con las que se tiene convenio de intercambio estudiantil.

La Dirección y la Sección de Movilidad Académica y Administrativa desarrollan un intenso trabajo para apoyar las unidades académicas que requieren sustituir la planta docente que se estaría jubilando, por una fuerte inversión institucional que tuvo como prioridad el fortalecimiento del Programa de Becas en el Exterior para la renovación de cuadros docentes con posgrados. La OAICE desarrolló durante el período 2005-2012 un plan de acción que representó un incremento significativo del número de becas para estudios de doctorado otorgadas por la Institución anualmente, cuyas acciones estaban encaminadas a fortalecer el programa de relevo generacional del personal académico.

Esta modalidad permite hacer, del proceso de internacionalización, un soporte directo a la renovación del cuadro profesoral institucional, pues se asigna contenido presupuestario a esta iniciativa y, además, se contó con financiamiento de algunos organismos de cooperación y de universidades contrapartes, por medio de convenios de cofinanciamiento suscritos con la UCR.

En el ámbito de la gestión, con poco más de veinte funcionarios y funcionarias distribuidos en las distintas secciones de la Oficina, se abre la oportunidad de participación y capacitación a las jefaturas de Sección, incluida la Asesoría Legal, en actividades en el exterior, lo cual contribuye a ampliar su visión de mundo, conocer buenas prácticas desarrolladas en el ámbito de las relaciones internacionales de otras universidades en distintos continentes, establecer contactos que servirán de apoyo para el seguimiento de futuras actividades de cooperación y aprender de diversos temas de interés mundial en el ámbito de la educación superior, para enriquecer sus bases para el desarrollo de sus gestiones y modernizar procesos a su cargo.

Los avances en las tecnologías de la información y la evolución en la visión estratégica institucional permiten que la OAICE cuente durante este período con un sitio web en el que se facilita información de sus principales actividades y en el que se promueve la participación de la comunidad universitaria en diversas oportunidades de cooperación y de formación en el exterior.

Paralelo al fortalecimiento de la OAICE, otra importante estrategia organizacional implementada por la UCR durante esta etapa es la definición, en el 2008, de las políticas institucionales (tabla 2) que regirán en el quinquenio 2010-2014, a diferencia de años anteriores que se establecían anualmente.

O’neal-Coto (2009), en relación con las políticas institucionales para la proyección de UCR para el quinquenio 2010-2014, señala que: 
Por primera vez en su historia la Universidad de Costa Rica ha creado las políticas que orientarán y regirán todas sus actividades sustantivas en los próximos años, a partir de una metodología participativa y las ha organizado en 5 grandes ejes y 14 temas. (p. 1)

En este mismo sentido O'Neal-Coto manifiestó que el Consejo Universitario destaca que:

... la organización de las políticas en los 5 ejes establecidos y los 14 temas permitirá a las diferentes instancias universitarias articular con mayor facilidad cada política a sus planes de desarrollo, programas, proyectos, convenios y actividades intra o interuniversitarias, así como a las solicitudes de apoyo presupuestario. $(2009$, p. 1)

El eje número uno sobre Universidad-Sociedad sitúa los temas y las políticas asociadas a la interacción Universidad-vs- comunidad nacional e internacional (tabla 2). Por lo que se identificaron aquí las áreas prioritarias para la UCR en su proceso de internacionalización, como un medio para contribuir a cumplir su misión con la sociedad: establecimiento de relaciones internacionales de mutuo beneficio; apoyo a iniciativas formales, tales como tratados que favorezcan el desarrollo de la sociedad en ámbitos clave; la promoción de la movilidad académica y estudiantil; y la exploración de diversas modalidades de estudio de posgrado.

Tabla 2

Políticas de internacionalización (aprobadas por el Consejo Universitario en sesión extraordinaria 5296, artículo único, del 13-10-2008) de la UCR para los años 2010- 2014

\section{Eje 1: Universidad y Sociedad Tema: Políticas de Internacionalización}

1.3.1. Promoverá las relaciones internacionales y de cooperación para fortalecer sus actividades sustantivas por medio de la participación en iniciativas internacionales de carácter interinstitucional y la firma de acuerdos y convenios.

1.3.2. Apoyará la firma de tratados que repercutan favorablemente en la conservación y rescate del medio ambiente, la reducción del riesgo en materia de desastres, la mitigación de la pobreza, la seguridad alimentaria, la vulnerabilidad y las exclusiones sociales, la defensa de las identidades culturales, la equidad y la integración social, el acceso a los servicios básicos y la eliminación de las limitantes al desarrollo humano sostenible.

1.3.3. Promoverá y facilitará la movilidad internacional del personal docente, administrativo y de la población estudiantil, como un medio para fortalecer la educación superior pública.

1.3.4. Impulsará los espacios de análisis institucional sobre la conveniencia de las diversas modalidades de estudios de posgrado (posgrados conjuntos y doble titulación, entre otros).

Nota: Elaboración propia con base en: La Gaceta Universitaria 40-2008 del 21-11-2008 (UCR, 2008). 
La implementación de esta política de internacionalización se favorece durante este período, mediante la actualización de la normativa universitaria e implementación de otras estrategias administrativas.

En el año 2011 se realizan reformas integrales tanto al Reglamento del Programa de Becas para estudios en el exterior denominado "Reglamento del Régimen de Beneficios para el Mejoramiento Académico de los Profesores y Funcionarios en Servicio" que estaba establecido desde 1975, con el propósito de mejorar las condiciones del profesorado becario en este régimen al reincorporarse y formalizar compromisos que deberán asumir con la Institución. De igual manera, se actualiza el Reglamento de la OAICE que fue establecido desde 1977 (UCR, 2011; 2012).

Asimismo, se da un giro en la gestión de convenios internacionales en el que se busca crear un cambio de cultura organizacional, por medio del estímulo a las unidades académicas para formular planes de trabajo concretos que justifiquen la necesidad de establecer nuevos convenios, con el fin de favorecer un mayor aprovechamiento de los convenios existentes y disminuir la cantidad de acuerdos generales que no fijaban claros compromisos.

Por otro lado, se establecen nuevas pautas de negociación con universidades contrapartes extranjeras que buscan explorar posibilidades conjuntas de financiamiento para estudios de posgrado de personal docente y administrativo, así como brindar beneficios adicionales a estudiantes para realizar intercambios, debido al importante reto que tiene la Universidad para este período de movilizar a sus estudiantes al exterior y tener un mejor aprovechamiento de los convenios de movilidad.

Etapa 6: Hacia la optimización de la gestión y potenciación de nuevos ámbitos del proceso de internacionalización de la UCR: Para el período de mayo 2012 a diciembre 2013 se identifican las primeras instancias de una nueva organización en el proceso de internacionalización. En este se da continuidad a las primeras etapas del modelo de internacionalización propuesto para la UCR y se empiezan a desarrollar nuevas estrategias organizacionales y programáticas como las propuestas por Gacel-Ávila (2009) en su modelo, para favorecer una planificación estratégica significativa que permita consolidar las acciones de movilidad académica existentes, fortalecer la calidad de los procesos de gestión de la internacionalización, favorecer una mayor movilidad de estudiantes UCR hacia universidades extranjeras y diversificar las relaciones de cooperación con la región de Asia.

En este período la internacionalización sigue teniendo un papel prioritario en la UCR y se mantiene un fuerte compromiso para seguir impulsando sus actividades estratégicas de movilidad del conocimiento.

En esta nueva etapa, la UCR da continuidad y enfatiza la importancia de ampliar la movilidad estudiantil al exterior, mediante la consolidación de apoyo complementario de la Vicerrectoría de Vida Estudiantil para traslado aéreo y de nuevos programas especiales de oferta académica internacional. Estos programas han permitido la generación de recursos para brindarles complemento económico a estudiantes de las unidades académicas que los ofrecen, de manera que puedan realizar uno o dos semestres de estudio en esas universidades. También, se ha logrado instituir un fondo de apoyo a estudiantes de excelencia académica con beca de atención socioeconómica categoría 11, otorgándoles una beca completa para realizar uno o dos semestres de estudios en el exterior. 
Por otro lado, recientemente, se creó un nuevo programa (agosto 2013) denominado "Movilidad Estudiantil Internacional CONARE", mediante la resolución R-102-2013, con el fin de favorecer la movilidad estudiantil en el ámbito internacional, por medio de la participación en pasantías, proyectos de investigación conjuntos, foros, congresos, seminarios, para lo cual se otorga ayuda económica a estudiantes con beca UCR de atención socioeconómica para las categorías desde la 7ª a la 11ª (CONARE, 2013).

En lo que respecta a la movilidad de personal académico se siguen consolidando las relaciones de cooperación existentes con América Latina, América del Norte, y Europa. Adicionalmente, se amplía la vinculación con Asia, mediante la suscripción de nuevos convenios con universidades de prestigio de Corea del Sur y con la Fundación Corea para promover la enseñanza del idioma coreano y la cultura, mediante la colaboración de profesorado especialista en la enseñanza de ese idioma.

Con el fin de diversificar el impacto de las acciones de cooperación y promover espacios de análisis y reflexión en otros ámbitos del conocimiento de otras culturas, se da la apertura de diversas cátedras en la UCR, con la creación de la Cátedra de Estudios de Corea y el Este Asiático; Cátedra de Estudios de África y el Caribe y Cátedra Wilhelm y Alexander von Humboldt en Humanidades y Ciencias Sociales. (Jensen-Pennington, 2014).

Durante el periodo 2013-2016, la OAICE se rige bajo la dirección de la Dra. Julieta Carranza (2013; 2014), quien impulsó el mejoramiento de la calidad y la gestión estratégica de las diversas acciones vinculadas con el proceso de internacionalización de la UCR, mediante un nuevo proceso de "revisión" planteado en fase 5 por Knight (1994), de las estrategias organizacionales mencionadas por Gacel-Ávila (2009): impulso para la creación de nueva normativa, ordenamiento de procedimientos, promover estrategias para la internacionalización del currículo y la investigación, mejor coordinación de los servicios, y desarrollo de mayor profesionalización y capacitación del personal, a fin de favorecer un uso más eficiente de los recursos para promover un mayor efecto de integración de la internacionalización en todos los ámbitos sustantivos del quehacer institucional.

La OAICE $^{3}$ se caracteriza porque ha aumentando la conciencia institucional de la internacionalización y la cooperación internacional, asiste las iniciativas institucionales dirigidas a la realización de talleres, seminarios y capacitaciones para docentes con el fin de diseñar o "rediseñar" cursos o programas académicos e integrar la dimensión internacional, intercultural, global e interdisciplinaria en los contenidos de los cursos. Dicha Oficina apoya ampliamente las actividades de investigación que fomentan y construyen el proceso de internacionalización de la investigación institucional y facilita la articulación de la educación superior con los organismos gubernamentales nacionales e internacionales. Esto da muestra de que su proceso se está consolidando cada vez más, se nota que está pasando de ser un receptor pasivo a uno activo, dinámico, en el campo de la internacionalización, promueve el multilingüismo y está iniciando una labor muy importante en cuanto a preocuparse por revisar y evaluar, periódicamente y en forma crítica, la calidad del proceso de internacionalización institucional.

El modelo actual de internacionalización de la UCR ejemplifica cómo este proceso parte

3 En la actualidad, bajo la dirección de la Ing. Leonora de Lemos Medina. 
desde los orígenes institucionales con una visión de largo plazo, con profundo compromiso institucional y se nutre del apoyo internacional, pero sobre todo de un significativo aporte de la Institución. El éxito de este modelo se fundamenta en su capacidad para evolucionar y adaptarse a los diversos cambios que le plantea el escenario local, regional e internacional a la educación superior costarricense y, en particular, el panorama que enfrenta la Institución.

\section{Conclusión}

Como conclusión se retoman los hallazgos más destacados del presente estudio, catalogado como específicos, porque facilitaron recabar información comparativa sobre el desempeño cronológico del quehacer institucional en cuanto al proceso de internacionalización y la cooperación académica internacional, como sigue:

1. El proceso histórico de desarrollo de la internacionalización en la UCR ha sido visionario, evidencia una evolución progresiva y sostenida en el tiempo.

2. El modelo actual de internacionalización de la UCR es un proceso impulsado desde los orígenes institucionales con alto compromiso y significativo aporte de la propia Institución y se complementa con apoyo internacional. Se pudo constatar que el éxito de este modelo se relaciona con su autonomía y visión a largo plazo de sus líderes, y en su capacidad para evolucionar y adaptarse a los diversos cambios planteados en el escenario internacional de la educación superior.

3. La UCR, en las últimas dos décadas, ha tenido una importante evolución en los procesos de gestión de la internacionalización, por lo que la Oficina de Asuntos Internacionales y Cooperación Externa, como ente coordinador de este proceso, ha logrado importantes avances.

4. Sin detrimento de los avances recién mencionados, en nuestro estudio comprobamos que la información de un gran número de actividades de internacionalización de la UCR se encuentra dispersa en toda la Institución y no está bien sistematizada, lo que no permite visualizar con facilidad y precisión la magnitud del esfuerzo de inversión en las múltiples acciones al respecto. Esta situación ocasiona pérdida de oportunidades para hacer sinergias entre las diferentes gestiones y dificulta, igualmente, la evaluación y el seguimiento integral del desempeño de la Institución, que agilizaría una planificación estratégica más adecuada y un mejoramiento continuo.

\section{Referencias}

Araya, C. (1991). La Universidad de Costa Rica: Rasgos de su evolución histórica, 1940-1972. En Centro de Investigaciones Históricas, Universidad de Costa Rica (Comp.). Historia de la Educación Superior en Costa Rica, (115-201). San José, Costa Rica: Oficina de Publicaciones de la Universidad de Costa Rica. 
Carranza-Velásquez, J. y Marín-Méndez, W. M. (2013). Informe de Labores. San José: Autor.

Carranza-Velásquez, J. (2014). Informe de Labores - 2014. Recuperado de http://www.oaice. ucr.ac.cr/archivos/INFORME DE LABORES DE LA OAICE-2014.pdf

Consejo Nacional de Rectores (CONARE). (2013). Acta de la sesión No. 20-13. Recuperado de http://bit.ly/2aHo4lf

Davies, J. L. (1995). University Strategies for Internationalization in Different Institutional and Cultural Settings: A conceptual Framework. [Estrategias universitarias para la internacionalización en diferentes ámbitos institucionales y culturales: Un marco conceptual] En P. Blok (Ed.) Policy and Policy Implementation in Internationalization of Higher Education. EAIE Occasional Paper 8, 3-18. Amsterdam: European Association for International Education (EAIE).

De Wit, H. (2002). Internationalization of Higher Education in the United States of America and Europe: A Historical, Comparative, and Conceptual Analysis. [Internacionalización de la educación superior en los Estados Unidos de América y Europa: Un análisis histórico, comparativo y conceptual]. USA: Greenwood Publishing Group.

Dengo-Obregón, M. E. (2003). El desarrollo de la formación docente en Costa Rica. En J. M. Salazar-Mora (Ed.) Historia de la educación costarricense, (pp. 244-245). San José, EUNED.

Didou Aupetit, S. (2007). La internacionalización de la educación superior en América Latina: Oportunidades y desafíos. In Conferencia dictada en el Pabellón Argentina de la Ciudad Universitaria, Córdoba.

Gacel-Ávila, J. (2000). La dimensión internacional de las universidades mexicanas. Revista Educación Superior y Sociedad, 11 (1 y 2), 121-142.

Gacel-Ávila, J. (2009). Marco teórico: Modelo de oficinas de relaciones internacionales. En Red SAFIRO II, Casos prácticos para la gestión de la internacionalización en universidades, 6 32). España: Oficina de Gestión de Proyectos Internacionales de la Universidad de Alicante.

Garita-Bonilla, L. (1989). Informe Rector mayo 1988 - mayo1989. San José, Costa Rica: Oficina de Publicaciones de la Universidad de Costa Rica. Recuperado de http://www. rectoria.ucr.ac.cr/site/wp-content/uploads/2013/11/1988-1989.pdf

Garita-Bonilla, L. (1992). Informe Rector mayo 1991 - mayo 1992. San José, Costa Rica: Oficina de Publicaciones de la Universidad de Costa Rica. Recuperado de http://www. rectoria.ucr.ac.cr/site/wp-content/uploads/2013/11/1991-1992.pdf 
Garita-Bonilla, L. (1996). Informe Rector mayo 1995 - mayo 1996. San José, Costa Rica: Oficina de Publicaciones de la Universidad de Costa Rica. Recuperado de http://www. rectoria.ucr.ac.cr/site/wp-content/uploads/2013/11/1995-1996.pdf

Gómez-Redondo, M. (1999). Propuesta para la creación de una Unidad de Información Especializada en Asuntos Internacionales y Cooperación Externa para la Universidad de Costa Rica (Tesis de licenciatura). Universidad de Costa Rica. Sede Rodrigo Facio.

González-García, Y. (2012). Informe de Gestión Rectoría 2004-2012. San José, Costa Rica: Oficina de Publicaciones de la Universidad de Costa Rica. Recuperado de http://www. rectoria.ucr.ac.cr/site/wp-content/uploads/2013/11/Informe-de-Labores-2011-2012.pdf

Gutiérrez, F. (1982). Educación como praxis política. San José, Costa Rica: Nueva Década.

Herrera-Zavaleta, R. y Rodríguez-Molina, M. E. (1994). Universidad y reformismo en Costa Rica. San José: EUCR.

Jensen-Pennington, H. (2014). Informe Anual del Rector 2013 - 2014. San José, Costa Rica: SIEDIN. Recuperado de http://www.rectoria.ucr.ac.cr/site/wp-content/uploads/2013/10/ Informe-del-Rector-2013-2014.pdf

Knight, J. (1994). Internationalization: Elements and Checkpoints. [Internacionalización: Elementos y controles]. CBIE Research. Canadian Bureau of International Education, 7, (1-14). Recuperado de http://www.cbie-bcei.ca/wp-content/uploads/2014/01/ Internationalization-Elements-and-Checkpoints.pdf

Knight, J. (2005). Un modelo de internacionalización: Respondiendo a nuevas realidades y retos. En De Wit, H., Jaramillo, I., Gacel-Ávila, J. y Knight, J. (Ed.), La dimensión internacional de la educación superior en América Latina. (1-38). Washington D.C.: Banco Mundial.

Macaya-Trejos G. (2004). Informe Rector 1996 - 2004. San José, Costa Rica. Recuperado de http://www.rectoria.ucr.ac.cr/site/wp-content/uploads/2004/07/Informe-1996-2004.pdf

Macaya-Trejos G. (1998). Informe del Rector de la Universidad de Costa Rica. Recuperado de http://boletin.cu.ucr.ac.cr/docum/informe-rector.pdf

O'neal-Coto, K. (2009). Políticas quinquenales guiarán el quehacer de la UCR hasta el 2014. Boletín Electrónico Presencia Universitaria. Recuperado de http://www.odi.ucr.ac.cr/ boletin/index.php?option $=$ com content\&task $=$ view\&id $=593$ 
Rodríguez-Vega, E. (1972). Informe Rector 1971 - 1972. San José, Costa Rica: Oficina de Publicaciones de la Universidad de Costa Rica.

Rodríguez-Vega, E. (1973). Informe Rector 1972 - 1973. San José, Costa Rica: Oficina de Publicaciones de la Universidad de Costa Rica. Recuperado de http://www.rectoria.ucr. ac.cr/site/wp-content/uploads/2013/11/1972-1973.pdf

Rudzki, R. (1998). The Strategic Management of Internationalization-Towards a Model of Theory and Practice. [La administración estratégica de la internacionalización- Hacia un modelo teórico-práctico] (Tesis doctoral). Newcastle, School of Education, University of Newcastle, Australia.

Sittenfeld-Appel, A. (2012). Informe de Gestión Oficina de Asuntos Internacionales y Cooperación Externa. San José: Autor.

Universidad de Costa Rica (UCR). (s. f.). Expediente 30.11. Reestructuración Asuntos Internacionales. San José. Rectoría, Universidad de Costa Rica. Manuscrito inédito.

UCR. (2015). UCR en cifras. Recuperado de http://www.ucr.ac.cr/acerca-u/ucr-en-cifras.html

UCR. (1979). Acuerdos Definitivos Originados en el III Congreso Universitario. (1971-1972). San José: Universidad de Costa Rica.

UCR. (2006). Estatuto Orgánico de la Universidad de Costa Rica. Recuperado de http://www. cu.ucr.ac.cr/normativ/estatuto organico.pdf

UCR. (2013). Plan Estratégico Institucional 2013-2017. Recuperado de http://oplau.ucr.ac.cr/ phocadownload/plan estrategico/Plan estrategico institucional 2013-2017.pdf

UCR. (2008). Políticas de la Universidad de Costa Rica para los años 2010-2014. Recuperado de http://www.cu.ucr.ac.cr/normativ/politicas institucionales 2010-2014.pdf

UCR. (2011). Reglamento del Régimen de Beneficios para el Mejoramiento Académico en el Exterior para el Personal Docente y Administrativo en Servicio. Recuperado de http:// www.cu.ucr.ac.cr/normativ/regimen beneficios academico.pdf

UCR. (2012). Reglamento de la Oficina de Asuntos Internacionales y Cooperación Externa (OAICE). Recuperado de http://www.cu.ucr.ac.cr/gacetas/2011/a03-2011.pdf 